\title{
Unemployment Dynamics and Endogenous Unemployment Insurance Extensions*
}

\author{
W. Similan Rujiwattanapong ${ }^{\dagger}$
}

May 1, 2019

\begin{abstract}
This paper investigates the impact of endogenous unemployment insurance (UI) extensions on the dynamics of unemployment and its duration structure in the US. Using a search and matching model with worker heterogeneity, I allow for the maximum UI duration to depend on unemployment and for UI benefits to depend on worker characteristics. UI extensions have a large effect on long-term unemployment during the Great Recession via job search responses and a moderate effect on total unemployment via job separations. Disregarding rational expectations about the timing of UI extensions implies an overestimation of the unemployment rate by over 2 percentage points.
\end{abstract}

JEL Classification. E24, E32, J24, J64, J65.

Keywords. Business cycles, long-term unemployment, unemployment insurance, unemployment duration, rational expectations

\footnotetext{
${ }^{*}$ I am indebted to Morten Ravn for invaluable guidance and support, and to Fabien PostelVinay and Vincent Sterk for very helpful discussions and suggestions. I also want to thank Wei Cui, Gregor Jarosch, Fatih Karahan, Jeremy Lise, Kurt Mitman, Suphanit Piyapromdee, Shouyong Shi, Ludo Visschers and Randall Wright as well as seminar participants at Aarhus University, Bank of Thailand, University of Bath, Birkbeck University of London, GRIPS, Hitotsubashi University, University of Konstanz, Queen Mary University of London, University of Tokyo, UCL, Bristol Search and Matching Workshop, and Nordic summer symposium in Macroeconomics for helpful comments and conversations. This paper was previously circulated as "Long-term Unemployment Dynamics and Unemployment Insurance Extensions".

${ }^{\dagger}$ Aarhus University and Centre for Macroeconomics. Mailing Address: Department of Economics, Aarhus BSS, Aarhus University, Fuglesangs Alle 4, Aarhus V, 8210, Denmark. Email: rujiwatt@econ.au.dk.
} 


\section{Introduction/Motivation}

From the onset of the Great Recession, the US labour market exhibits dynamics never seen before in previous recessions. Underlying persistently high unemployment is an unprecedented rise in long-term unemployment (represented by those whose unemployment duration is greater than 6 months) as seen in Figure 1. Long-term unemployment had always been below a quarter of total unemployment apart from two occasions: the Great Recession when it represented almost half of the total unemployment population and the early 1980s recession where it represented a quarter of total unemployment. ${ }^{1}$

This paper investigates the impact of endogenous unemployment insurance (UI) extensions on the dynamics of unemployment and its duration structure under rational expectations using a search and matching model in general equilibrium. Whilst the analysis applies to cyclical fluctuations in general, the focus of the paper is on the Great Recession, the period during which UI eligible unemployed workers could receive benefits for a maximum of 99 weeks (whereas the standard maximum UI duration is 26 weeks) as depicted in Figure 2 From the same figure, it can be seen that the maximum UI duration has been extended in every recession since late 1950s, and its generosity, measured by weeks of maximum UI duration, has been increasing over time (except for one extension in the early 1980s). There are primarily two types of UI extensions in the US: (1) automatic UI extensions that are in the federal laws since 1970s and are triggered by the state (insured) unemployment rate, and (2) discretionary UI extensions that are issued specifically during recessions. ${ }^{2}$ It is the first type that endogenises UI extensions and makes them countercyclical. ${ }^{3}$

Based on this countercyclical UI system, I extend the standard search and matching model to incorporate unemployment-dependent UI extensions, variable search intensity, endogenous separations, on-the-job search, and worker's hetero-

\footnotetext{
${ }^{1}$ Abraham, Haltiwanger, Sandusky, and Spletzer (2016) find that long-term unemployed workers face worse labour market outcomes in terms of re-employment probabilities and subsequent earnings even when controlled for individual heterogeneity.

${ }^{2}$ The automatic extensions are called extended benefits (EB) whilst the ad-hoc extensions are under different names. For example, in 1958, the programme was called Temporary Unemployment Compensation Act (TUC), and in 1961, it was Temporary Unemployment Extended Compensation Act (TEUC). From 1991 onwards, the discretionary extensions have been under the name Emergency Unemployment Compensation (EUC).

${ }^{3} \mathrm{We}$ can also see from Figure 2 that both the automatic and discretionary extensions have been increasing in their generosity and that they are a feature of every recession since late 1950s.
} 
geneity in terms of productivity and benefit level. The job search decision of a worker depends not only on their UI status, benefit level, and individual productivity but also on the aggregate productivity and the unemployment rate which determine when and for how long UI extensions will occur.

Many empirical studies have documented how the labour market outcomes of unemployed workers can differ with respect to their UI status. These differences come in many forms including their unemployment duration and unemployment exit rate (Moffitt and Nicholson (1982), Moffitt (1985), Katz and Meyer (1990), Meyer (1990), Card and Levine (2000)), job search intensity (Krueger and Mueller (2010, 2011)), and consumption (Gruber (1997)). Katz and Meyer (1990) find a large fraction of UI recipients expect to be recalled and represent over half of the unemployment duration in the sample. This is related to Fujita and Moscarini (2015) who show that the recall rate rises during recessions. I provide further empirical evidence that insured unemployed workers have a lower unemployment exit rate than the uninsured and this gap widened during the Great Recession when UI extensions took place.

There is a large literature studying the effects of the recent UI extensions on the unemployment exit rate and total unemployment during the Great Recession. Empirical studies include (but not limited to) Farber and Valletta (2011), Fujita (2011), Valletta and Kuang (2010), Aaronson, Mazumder, and Schechter (2010), Mazumder (2011), Rothstein (2011), Barnichon and Figura (2014), and Hagedorn, Karahan, Manovskii, and Mitman (2019). Most of these studies focus on the microeconomic effect of the UI extensions, namely, the impact on the probability of exiting unemployment or on the job search efforts of the unemployed. They found a small but significant impact of UI extensions. A notable exception is Hagedorn et al. (2019) as they take into account the response of job creation to benefit extensions and find a larger effect on unemployment.

A benefit of using a general equilibrium model is that I can distinguish between the microeconomic and general equilibrium effects of UI extensions on unemployment. I find that UI extensions contribute to a 0.9-1.8 percentage point (pp) increase in unemployment under the micro effect during the Great Recession which is consistent with existing empirical estimates. ${ }^{4}$ I find that the general equi-

\footnotetext{
${ }^{4}$ Existing estimates are in the range of 0.1-1.8pp. Fujita (2011) finds the UI extensions contribute to a $0.8-1.8 \mathrm{pp}$ increase in the unemployment rate during the Great Recession. Aaronson et al. (2010)'s estimates are between 0.5-1.25pp. Valetta and Kuang (2010)'s estimate is 0.4pp. Rothstein (2011)'s estimates are between 0.1-0.5pp.
} 
librium effect of UI, where worker-firm match formation/separation decisions are taken into account, is larger and similar to results from Hagedorn et al. (2019). In this paper, however, the additional effect is from the match separation margin. ${ }^{5}$

Studies on the effects of UI extensions in general equilibrium are conducted by Mitman and Rabinovich (2014) on jobless recoveries, Faig, Zhang and Zhang (2016) on the volatility of unemployment and vacancies, and Nakajima (2012) whose focus is on the Great Recession. ${ }^{6}$ The model in this paper is most similar to that in Mitman and Rabinovich (2014) and departs from theirs in two crucial aspects: (1) the endogeneity of UI extensions and (2) the heterogeneous job finding rates.

In their model, UI extensions are exogenous and assumed to last forever (i.e., agents have adaptive expectations). In my model, I assume that UI extensions are totally systematic, and agents have rational expectations regarding the timing and the length of these extensions which are governed by the unemployment rate, just like in the US economy. Agents in my model would therefore respond less strongly to UI extensions than in their model, in terms of both the job search intensity and the decision to form or dissolve a match. Additionally, workers in my model optimally choose their job search intensity whilst job search is fixed in their model. Therefore, unemployed workers in my model have heterogeneous job finding rates according to their UI status and benefit level whilst there is a single job finding rate in their model. I show in the empirical section that insured and uninsured unemployed workers do have different job finding rates. Heterogeneity in the job finding rates is crucial in explaining the unemployment duration structure in the US labour market. Wiczer (2015) shows that a single job finding rate implies an average unemployment duration and long-term unemployment that are just over half of what we observed in the data. This point regarding an inadequacy of a single job finding rate is key to the results in this paper. ${ }^{7}$

This paper also relates to the literature on the incidence of long-term unemployment and worker heterogeneity. Ahn and Hamilton (2019) use a non-linear state space model to uncover the unobserved heterogeneity of workers' unemployment

\footnotetext{
${ }^{5}$ Henceforth, I define job separations as employment-to-unemployment transtions.

${ }^{6}$ Nakajima (2012) studies an economy with transitional dynamics and finds that the UI extensions contribute to a $1.4 \mathrm{pp}$ increase in the unemployment rate.

${ }^{7}$ In Rujiwattanapong (2017), I show that a single job finding rate for insured unemployed workers hardly affects the distribution of unemployment durations. In this paper, I allow for the job finding rates of insured unemployed workers to vary with the benefit level and individualspecific productivity.
} 
exit rate. Worker heterogeneity is the focus of Hornstein (2012) in accounting for unemployment dynamics with different durations. Ravn and Sterk (2017) consider the difference in unemployment exit rates together with incomplete markets and price rigidities to study the amplification mechanism on unemployment. Carrillo-Tudela and Visschers (2014) study the role of unemployed workers' occupational mobility on the fluctuations of unemployment and its duration over business cycles. Kroft, Lange, Notowidigdo, and Katz (2016) analyse the impact of a genuine duration dependence in unemployment exit rate on the rise of longterm unemployment. They find little account for the observable characteristics of workers. Ahn (2016) extends Ahn and Hamilton (2019) to incorporate observable characteristics of the workers (but not their UI status).

My paper considers a degree of observed and unobserved worker heterogeneity where the former comes from the UI status and benefit level, and the latter is from the worker's productivity, all of which affect the job finding rate. I also estimate the same model in Ahn and Hamilton (2019) using Maximum Likelihood and show that their interpretation of unobserved heterogeneity is related to the UI status in my model since insured unemployed workers have a lower unemployment exit rate. I find that worker productivity does not matter much once the UI status and benefit level are taken into account.

The main contributions of this paper are twofold. First, it quantifies the microeconomic and general equilibrium effects of UI extensions on unemployment and its duration structure. Second, it demonstrates the importance of rational expectations regarding the timings of endogenous UI extensions. The framework is useful for policy experiments to study the mechanisms through which UI extensions affect the aggregate labour market.

To preview the results, I find that UI extensions account for 10-30 percent of the rise on unemployment during the Great Recession, but the UI effect is non-linear and of a smaller magnitude in other recessions. The main mechanism through which UI extensions impact unemployment is the job separation margin whereas the job search behaviour is most important for long-term unemployment. I show that a failure to take into account rational expectations about the timing of UI extensions implies an overestimation of unemployment by more than $2 \mathrm{pp}$.

The paper is organised as follows. Section 2 discusses some motivating data on UI extensions and long-term unemployment during the Great Recession. Section 3 describes the model. Section 4 discusses the calibration exercise. Section 5 
analyses the results under the baseline model and counterfactual experiments. Section 6 concludes.

\section{Empirical Evidence}

I examine the empirical evidence that (1) workers currently receiving UI benefits are less likely to find a job than workers without UI, and that (2) this gap between insured and uninsured workers' job finding rates was more pronounced during the Great Recession. These findings are important for explaining the surge in long-term unemployment. I study the transition rates from unemployment to employment, unemployment and out-of-labour-force (OLF) (namely UE, UU, and UOLF rates respectively), as well as the distributions of unemployment duration between 2006 and 2014 according to the UI status and several observable characteristics of unemployed workers including age, education, gender, industry, occupation, reasons for unemployment, and recall expectation. They are constructed from the CPS Basic Monthly Data and CPS Displaced Worker, Employee Tenure, and Occupational Mobility Supplement. ${ }^{8}$

Job findings Table 1 shows that the job finding rate of current UI recipients is generally smaller than that of non-UI recipients, and this gap became larger during the Great Recession. In January 2008, when there was no UI extensions, unemployed workers with and without UI found a job at rate 21 percent and 28 percent respectively, whilst in January 2010, when the maximum UI duration was 99 weeks, the job finding rate of insured unemployed workers fell dramatically to 7 percent, 11pp smaller than that of the uninsured unemployed. The findings remain the same when I control for other observable worker characteristics as shown in Table A.1 of Appendix A. ${ }^{9}$

To stay unemployed or to exit the labour force? Accompanying the drop in job findings during the Great Recession are an increase in the UU rate and little

\footnotetext{
${ }^{8}$ I consider workers whose age is 16 years or older. Since the workers' UI history is only surveyed when the supplement takes place (every two years), I obtain the transition rates by merging the January supplement data with the basic monthly data for the following February. Transition rates are calculated as a fraction of unemployed workers conditioned on their UI status (i.e., whether they are currently receiving UI benefits or not) and possibly other characteristics moving into either employment, unemployment, or OLF in the following month.

${ }^{9}$ Specifically, insured unemployed workers had a lower job finding rate than uninsured unemployed workers in most subgroups in 2008 and in all subgroups in 2010. The job finding rates from 2008 to 2010 for current UI recipients in most subgroups fell by a larger magnitude than for non-UI recipients.
} 
change in the UOLF rate. This is the case regardless of the UI status. Table 1 shows that from 2008 to 2010 the UU rate increased by 16pp for workers with UI and by $12 \mathrm{pp}$ for workers without UI. At the same time, Table 1 shows that the fall in the UOLF rate was only 2(3)pp for the (un)insured unemployed. This suggests that UI extensions do not significantly affect the labour force exit rate. ${ }^{10}$ The same results apply when I condition on other observable worker characteristics as shown in Table A.2 and A.3 of Appendix A.

Distribution of unemployment duration The share of long-term unemployed workers who were current UI recipients rose substantially from 15 percent to 51 percent between 2008 and 2010 as shown in Figure 3. This large increase in the share of current UI recipients during the Great Recession is a prominent feature in all subgroups considered as shown in Table A.4 of Appendix A. In Figure 3, I contrast this with the shares of insured workers amongst the newly unemployed that did not increase as much.

These empirical findings motivate the model in the next section to feature a degree of worker heterogeneity and endogenous job search intensity which together imply heterogeneous job finding probabilities.

\section{Model}

I present a search and matching model à la Pissarides (2000) with endogenous separations, variable job search intensity, and on-the-job search. On top of this, I allow for the maximum UI duration to depend on the unemployment rate. Workers differ in terms of UI status, benefit level, and labour productivity. Only the last attribute is permanent. These differences not only affect how hard workers search for jobs, but also how likely worker-firm matches are formed and separated. Workers with higher outside options, e.g. those with higher (potential) UI benefits, tend to exit unemployment more slowly and are more likely to quit. I begin this section by specifying technology and preferences of workers and firms as well as the UI duration policy and UI eligibility. I then discuss wage determination, and finally I present the equilibrium conditions.

\footnotetext{
${ }^{10}$ For simplicity, the model I present in the following section will therefore not feature the labour force participation margin. Barnichon and Figura (2014) also find that UI extensions did not affect the labour force participation rate in the past 35 years.
} 


\subsection{Technology and Preferences}

Time is discrete and runs forever. There are two types of agents in the economy: a continuum of workers of measure one and a large measure of firms. Workers have either high or low productivity (type $H$ or $L$ ). A match consists of one worker and one firm whose output depends on the aggregate productivity $(z)$, its match-specific productivity $(m)$, and type- $i$ worker's productivity $\left(\eta_{i}\right)$. Specifically, $y_{i t}(m)=z_{t} \times m \times \eta_{i} \quad ; i \in\{H, L\}$. The price of output $y_{i t}(m)$ is normalised to one. The aggregate productivity $z$ has an $\operatorname{AR}(1)$ representation: $\ln z_{t}=\rho_{z} \ln z_{t-1}+\varepsilon_{t}$ where $\varepsilon_{t} \sim N\left(0, \sigma_{z}^{2}\right)$ is the only exogenous shock in the model. The match-specific productivity $m$ is drawn at the start of every new worker-firm match from a distribution $F(m)$. A given match gets to keep its match quality $m$ to the next period with probability $1-\lambda$, otherwise it redraws a new $m$ from $F(m)$ for its production next period. $\eta_{i}$ is type- $i$ worker's productivity where $\eta_{L}<\eta_{H} \equiv 1$. A worker's productivity is permanent.

With respect to preferences, both workers and firms are infinitely-lived and risk-neutral. They discount future flows by the same factor $\beta \in(0,1)$. Workers are either employed $(e)$, insured unemployed $(U I)$, or uninsured unemployed $(U U)$. They exert job search effort $s$ at the cost of $v_{e}(s)$ when employed, and at the cost $v_{u}(s)$ when unemployed regardless of their UI status. These search cost functions $v_{e}($.$) and v_{u}($.$) are strictly increasing and convex. During unem-$ ployment, workers' job search intensity may vary depending on their UI status, benefit level, and both aggregate and individual productivities, whilst during employment, it depends on their match quality and both aggregate and individual productivities. ${ }^{11}$ For employment status $j \in\{e, u\}$, a worker's period utility flow is $c_{i}-v_{j}(s)$ where $c_{i}$ is type- $i$ worker's consumption:

$$
c_{i t}= \begin{cases}w_{i t}(m, \tilde{m}) & \text { if employed at match quality } m \\ h+b_{i}(\tilde{m}) & \text { if insured unemployed } \\ h & \text { if uninsured unemployed }\end{cases}
$$

\footnotetext{
${ }^{11}$ Unemployment duration could be an important factor since the insured unemployed closer to benefit exhaustion (or with a higher rate of exhaustion) search harder for jobs. I allowed for unemployment duration to be an individual state variable and find that the results remain largely the same. This is due to the risk neutrality assumption. If workers are instead risk averse, their job search response to unemployment duration is expected to be stronger but such analysis is beyond the scope of the paper.
} 
where $w_{i}(m, \tilde{m})$ is the wage of type- $i$ worker that depends on $m$, the current match quality, and $\tilde{m}$, the match quality in her most recent employment. $h$ can be interpreted as home production or leisure flow during unemployment. $b_{i}(\tilde{m})$ is the UI benefit of type- $i$ worker with match quality $\tilde{m}$ in her most recent employment. I describe the UI system and the wage determination in the next subsections.

Firms are either matched with a worker or unmatched. Matched firms sell output, pay negotiated wage to their workers, and pay lump-sum tax $\tau$ to finance the UI payment. A match is exogenously separated at rate $\delta$, and an endogenous separation can occur when the value of a worker being matched to a firm or vice versa is negative. When firms are unmatched with a worker, they post a vacancy at cost $\kappa$ and cannot direct their posting to a specific type of workers.

\subsubsection{UI Duration Policy and UI Eligibility}

UI Duration The maximum UI duration is captured by the variable $\phi\left(u_{t}\right)$. Specifically, insured unemployed workers exhaust their UI benefits at the rate

$$
\phi\left(u_{t}\right) \equiv \phi_{L} \mathbb{1}\left\{u_{t} \geq \bar{u}\right\}+\phi_{H} \mathbb{1}\left\{u_{t}<\bar{u}\right\}
$$

where $\phi_{L}<\phi_{H}$ implying that the UI exhaustion rate is a decreasing function of the unemployment rate $u_{t}$ in the economy. ${ }^{12}$ Since the inverse of $\phi\left(u_{t}\right)$ is the expected duration of receiving UI benefits, a fall in the rate implies a UI extension. This is set to mimic the rules for UI extensions in the US where they depend on the state unemployment rate (above which UI extensions are triggered). ${ }^{13}$ I can capture the observed increase in the generosity of UI extensions in the US by lowering in the value that $\phi_{L}$ takes. Economic agents can predict whether a UI extension will be triggered/terminated next period by keeping track of unemployment and relevant distributions.

UI Eligibility Upon losing a job, employed workers become uninsured at rate $1-\psi$. This reflects how some unemployed workers do not take up UI benefits. On top of this, insured unemployed workers lose UI eligibility after an unproductive meeting with a firm at rate $\xi$ to reflect how UI recipients' job search is monitored.

\footnotetext{
${ }^{12}$ This stochastic UI exhaustion is first used in Fredericksson and Holmlund (2001). Mitman and Rabinovich (2014), Faig, Zhang and Zhang (2016), and Rujiwattanapong (2017) treat this rate to be state-dependent.

${ }^{13}$ Specifically, during normal times $\left(u_{t}<\bar{u}\right)$, the UI exhaustion rate is $\phi_{H}$ which is set to imply a standard UI duration of 26 weeks. When the unemployment rate is high and above $\bar{u}$ (often in recessions), insured unemployed workers exhaust the benefits at a slower rate $\phi_{L}$.
} 
UI payment is financed each period by lump-sum tax $(\tau)$ levied on matched firms:

$$
\tau(1-u)=\sum_{i \in\{H, L\}} \sum_{\tilde{m}} u_{i}^{U I}(\tilde{m}) b_{i}(\tilde{m})
$$

where $u_{i}^{U I}(\tilde{m})$ is the number of type- $i$ insured unemployed workers whose UI benefit is $b_{i}(\tilde{m})$.

\subsubsection{Search and Matching}

Workers and unmatched firms meet via a meeting function $M(s, v)$ where $s$ is the aggregate search intensity, and $v$ is the number of job vacancies. The meeting function $M(.,$.$) has constant returns to scale and is strictly increasing and concave$ in its arguments. Market tightness can be defined as $\theta \equiv v / s$. The conditional job finding probability per unit of search is $\frac{M}{s}=M(1, \theta)$; therefore, the conditional job finding probability of type- $i$ worker with employment status $j$ is $s_{i}^{j} M(1, \theta) \equiv$ $p_{i}^{j}(\theta) .{ }^{14}$ Analogously, the probability that a firm meets a worker is $\frac{M}{v} \equiv q(\theta)$.

\subsubsection{Timing}

1) Given $\left(u_{t}, z_{t}\right)$, production takes place, and UI duration policy $\phi\left(u_{t}\right)$ is set. 2) Workers choose job search effort. 3) Current matches draw a new $m$ at rate $\lambda .4$ ) Workers and unmatched firms meet. 5) Aggregate productivity $z_{t+1}$ next period is realised. 6) Matches/meetings dissolve. 7) $u^{U I}$ lose UI eligibility at rate $\phi\left(u_{t}\right)$ if not meeting a firm, or at rate $\phi\left(u_{t}\right)+\left(1-\phi\left(u_{t}\right)\right) \xi$ if a meeting has occurred. 8) Unemployment $u_{t+1}$ for next period is realised.

\subsubsection{Workers' Value Functions}

I first define the set of state variables as $\omega \equiv\left\{z, u, u_{i}, u_{i}^{U I}(\tilde{m}), u_{i}^{U U}, e_{i}(m) ; \forall m, \forall \tilde{m}\right.$ and $i \in$ $\{H, L\}\}$ where $u_{i}$ is the number of type- $i$ unemployed workers, $u_{i}^{U I}(\tilde{m})$ is the number of type- $i$ insured unemployed workers whose match quality in their most recent employment was $\tilde{m}, u_{i}^{U U}$ is the number of type- $i$ uninsured unemployed workers, and $e_{i}(m)$ is the number of type-i employed workers with current match

\footnotetext{
${ }^{14}$ The conditional job finding probability is essentially the probability that a worker meets a firm. The true job finding rate depends on whether such a meeting leads to a successful match formation.
} 
quality $m$.

Employed workers The value of a type- $i$ employed worker with last period's employment status and associated benefit level $j \in\{e(\tilde{m}), U I(\tilde{m}), U U\}$ is

$$
\begin{aligned}
W_{i}^{j}(m ; \omega)= & \max _{s_{i}^{e}(m ; \omega)} w_{i}^{j}(m ; \omega)-v_{e}\left(s_{i}^{e}(m ; \omega)\right)+\beta E_{\omega^{\prime} \mid \omega}[ \\
& \underbrace{(1-\delta)(1-\lambda)}_{\operatorname{Pr}(\text { stay matched, keep } m)}[\underbrace{\left(1-p_{i}^{e}(m ; \omega)(1-F(m))\right)}_{\operatorname{Pr}(\text { stay with current firm) }} W_{i}^{e(m)+}\left(m ; \omega^{\prime}\right) \\
& +\underbrace{p_{i}^{e}(m ; \omega)(1-F(m))}_{\operatorname{Pr}(\text { move to new firm) }} E_{m^{\prime} \mid m^{\prime}>m}\left[W_{i}^{e(m)+}\left(m^{\prime} ; \omega^{\prime}\right)\right]] \\
& +\underbrace{(1-\delta) \lambda}_{\operatorname{Pr}(\text { stay matched, new } m)} E_{m^{\prime}}[\underbrace{\left(1-p_{i}^{e}(m ; \omega)\left(1-F\left(m^{\prime}\right)\right)\right)}_{\operatorname{Pr}(\text { stay with current firm) }} W_{i}^{e(m)+}\left(m^{\prime} ; \omega^{\prime}\right) \\
& +\underbrace{p_{i}^{e}(m ; \omega)\left(1-F\left(m^{\prime}\right)\right)}_{\text {Pr(move to new firm) }} E_{m^{\prime \prime} \mid m^{\prime \prime}>m^{\prime}}\left[W_{i}^{e(m)+}\left(m^{\prime \prime} ; \omega^{\prime}\right)\right]] \\
& +\underbrace{\delta}_{\operatorname{Pr}(\text { match exogenously separated })}\left((1-\psi) U_{i}^{U I}\left(m, \omega^{\prime}\right)+\psi U_{i}^{U U}\left(\omega^{\prime}\right)\right)]
\end{aligned}
$$

where $W_{i}^{e(m)+}\left(m^{\prime} ; \omega^{\prime}\right) \equiv \max \left\{W_{i}^{e(m)}\left(m^{\prime} ; \omega^{\prime}\right),(1-\psi) U_{i}^{U I}\left(m, \omega^{\prime}\right)+\psi U_{i}^{U U}\left(\omega^{\prime}\right)\right\}$ showing that employed workers can always become unemployed (and get unemployment insurance at rate $1-\psi) .{ }^{15} U_{i}^{U I}(m)$ and $U_{i}^{U U}$ are respectively the value of the insured unemployed with benefit $b_{i}(m)$ and the value of the uninsured unemployed. The expressions for optimal search intensity of employed workers are in Appendix B.

Unemployed worker The difference between insured and uninsured workers stems from the period utility flow during unemployment. Amongst insured unemployed workers, their period utility flow can differ according to $\tilde{m}$, their match quality in the most recent employment, since UI benefits are attached to this variable. Therefore, the values of type- $i$ uninsured unemployed workers and insured

\footnotetext{
${ }^{15}$ Similar to the argument made in Krause and Lubik (2010), the current wage affects neither the decision of the employed worker to quit nor their job search effort due to the timing of the model and the bargaining structure. As a result, the bargaining set is still convex, and Nash bargaining is still applicable for the determination of wage. Shimer (2006) discusses the implications of having a non-convex payoff set.
} 
unemployed workers with benefit $b_{i}(\tilde{m})$ are respectively

$$
\begin{aligned}
& U_{i}^{U U}(\omega)=\max _{s_{i}^{U U}(\omega)} h-v_{u}\left(s_{i}^{U U}(\omega)\right)+\beta E_{m^{\prime} \omega^{\prime} \mid \omega}[\ldots \\
& \left.p_{i}^{U U}(\omega) \max \left\{W_{i}^{U U}\left(m^{\prime} ; \omega^{\prime}\right), U_{i}^{U U}\left(\omega^{\prime}\right)\right\}+\left(1-p_{i}^{U U}(\omega)\right) U_{i}^{U U}\left(\omega^{\prime}\right)\right] \\
& U_{i}^{U I}(\tilde{m}, \omega)=\max _{s_{i}^{U I}(\tilde{m}, \omega)} b_{i}(\tilde{m})+h-v_{u}\left(s_{i}^{U I}(\tilde{m}, \omega)\right) \\
& +\beta E_{m^{\prime} \omega^{\prime} \mid \omega}\left[p _ { i } ^ { U I } ( \tilde { m } , \omega ) \operatorname { m a x } \left\{W_{i}^{U I(\tilde{m})}\left(m^{\prime} ; \omega^{\prime}\right), \ldots\right.\right. \\
& \underbrace{\left(1-\phi_{u}\right)(1-\xi)}_{\operatorname{Pr}(\text { keep UI } \mid \text { meeting a firm })} U_{i}^{U I}\left(\tilde{m}, \omega^{\prime}\right)+\underbrace{\left(\phi_{u}+\left(1-\phi_{u}\right) \xi\right)}_{\operatorname{Pr}(\text { lose UI } \mid \text { meeting a firm })} U_{i}^{U U}\left(\omega^{\prime}\right)\} \\
& \left.+\left(1-p_{i}^{U I}(\tilde{m}, \omega)\right)\left(\left(1-\phi_{u}\right) U_{i}^{U I}\left(\tilde{m}, \omega^{\prime}\right)+\phi_{u} U_{i}^{U U}\left(\omega^{\prime}\right)\right)\right]
\end{aligned}
$$

Insured and uninsured unemployed workers when meeting a firm (with probability $p^{U I}($.$) and p^{U U}($.$) respectively) can either go into production and work$ or remain unemployed in the next period. The expressions for optimal search intensity of insured and uninsured unemployed workers are in Appendix B.

\subsubsection{Firms}

Matched firms The value of a matched firm with type- $i$ worker whose work history is $j \in\{e(\tilde{m}), U I(\tilde{m}), U U\}$ is

$$
\begin{aligned}
J_{i}^{j}(m ; \omega)= & y_{i}(m ; \omega)-w_{i}^{j}(m ; \omega)-\tau(\omega)+\beta E_{\omega^{\prime} \mid \omega}[\ldots \\
& (1-\delta)(1-\lambda)\left[\left(1-p_{i}^{e}(m ; \omega)(1-F(m))\right) J_{i}^{e(m)+}\left(m ; \omega^{\prime}\right)\right] \\
& \left.+(1-\delta) \lambda E_{m^{\prime}}\left[\left(1-p_{i}^{e}(m ; \omega)\left(1-F\left(m^{\prime}\right)\right)\right) J_{i}^{e(m)+}\left(m^{\prime} ; \omega^{\prime}\right)\right]\right]
\end{aligned}
$$

where $J_{i}^{e(m)+}\left(m^{\prime} ; \omega^{\prime}\right) \equiv \max \left\{J_{i}^{e(m)}\left(m^{\prime} ; \omega^{\prime}\right), 0\right\}$. Note that I have already imposed the free entry condition which implies the value of an unmatched firm is zero, i.e. $V(\omega)=0, \forall \omega$.

Unmatched firms Since the search is random, the distribution of workers' search intensity over employment status, UI status, benefit level, productivity type, and match quality of on-the-job searchers (as denoted by $\zeta$ 's in the following equation) enters the unmatched firm's problem and, therefore, becomes a part of the 
state variables. The value of an unmatched firm is

$$
\begin{aligned}
V(\omega)= & -\kappa+\beta q(\omega) E_{\omega^{\prime} \mid \omega}\left[\sum _ { i \in \{ H , L \} } \left(\sum_{m} \zeta_{i}^{e}(m ; \omega)(1-F(m)) E_{m^{\prime} \mid m^{\prime}>m}\left[J_{i}^{e(m)+}\left(m^{\prime} ; \omega^{\prime}\right)\right]\right.\right. \\
& \left.\left.+\sum_{m} \zeta_{i}^{U I}(m, \omega) E_{m^{\prime}}\left[J_{i}^{U I(m)+}\left(m^{\prime} ; \omega^{\prime}\right)\right]+\zeta_{i}^{U U}(\omega) E_{m^{\prime}}\left[J_{i}^{U U+}\left(m^{\prime} ; \omega^{\prime}\right)\right]\right)\right]
\end{aligned}
$$

where

$$
\begin{aligned}
\zeta_{i}^{e}(m) & =\frac{(1-\lambda) s_{i}^{e}(m) e_{i}(m)+\lambda f(m) \sum_{m} s_{i}^{e}(m) e_{i}(m)}{s} \\
\zeta_{i}^{U I}(m) & =\frac{s_{i}^{U I}(m) u_{i}^{U I}(m)}{s} ; \quad \zeta_{i}^{U U}=\frac{s_{i}^{U U} u_{i}^{U U}}{s} \\
s & =\sum_{i \in\{H, L\}}\left(\sum_{m}\left(s_{i}^{e}(m) e_{i}(m)+s_{i}^{U I}(m) u_{i}^{U I}(m)\right)+s_{i}^{U U} u_{i}^{U U}\right)
\end{aligned}
$$

\subsection{Wage and Surplus}

Wages are negotiated bilaterally using a generalised Nash bargaining rule. Type$i$ employed workers with previous employment status $j \in\{e(\tilde{m}), U I(\tilde{m}), U U\}$ and match quality $m$ receive

$$
w_{i}^{j}(m ; \omega)=\operatorname{argmax}\left(W S_{i}^{j}(m ; \omega)\right)^{\mu}\left(J_{i}^{j}(m ; \omega)\right)^{(1-\mu)}
$$

where $\mu$ is the worker's bargaining power. $W S_{i}^{j}$ is the surplus of type- $i$ employed workers with history $j$, and it is the difference between the value of working and the corresponding outside option. We can define the total match surplus $S_{i}^{j} \equiv$ $W S_{i}^{j}+J_{i}^{j}$. As a result, $W S_{i}^{j}=\mu S_{i}^{j}$ and $J_{i}^{j}=(1-\mu) S_{i}^{j}$. The surpluses of employed workers are as follows

$$
\begin{aligned}
W S_{i}^{e(\tilde{m})}(m ; \omega) \equiv & W_{i}^{e(\tilde{m})}(m ; \omega)-(1-\psi) U_{i}^{U I}(\tilde{m}, \omega)-\psi U_{i}^{U U}(\omega) \\
W S_{i}^{U I(\tilde{m})}(m ; \omega) \equiv & W_{i}^{U I(\tilde{m})}(m ; \omega)-(1-\phi(u))(1-\xi) U_{i}^{U I}(\tilde{m}, \omega) \\
& -(\phi(u)+(1-\phi(u)) \xi) U_{i}^{U U}(\omega) \\
W S_{i}^{U U}(m ; \omega) \equiv & W_{i}^{U U}(m ; \omega)-U_{i}^{U U}(\omega)
\end{aligned}
$$

The expressions for total match surpluses can be found in Appendix B. 


\subsection{Recursive Competitive Equilibrium}

A recursive competitive equilibrium is characterised by value functions, $W_{i}^{e(\tilde{m})}(m ; \omega)$, $W_{i}^{U I(\tilde{m})}(m ; \omega), W_{i}^{U U}(m ; \omega), U_{i}^{U I}(\tilde{m}, \omega), U_{i}^{U U}(\omega), J_{i}^{e(\tilde{m})}(m ; \omega), J_{i}^{U I(\tilde{m})}(m ; \omega), J_{i}^{U U}(m ; \omega)$, and $V(\omega)$; market tightness $\theta(\omega)$; search policy $s_{i}^{e}(m ; \omega), s_{i}^{U I}(m, \omega)$ and $s_{i}^{U U}(\omega)$; and wage functions $w_{i}^{e(\tilde{m})}(m ; \omega), w_{i}^{U I(\tilde{m})}(m ; \omega)$, and $w_{i}^{U U}(m ; \omega)$, such that, given the initial distribution of workers over productivity level, employment status, UI status, benefit level and match productivity, the government's policy $\tau(\omega)$ and $\phi(\omega)$, and the law of motion for $z$ :

1. The value functions and the market tightness satisfy the Bellman equations for workers and firms and the free entry condition, namely, equations (2), (3), (4), (5), and (6).

2. The search decisions satisfy the FOCs for optimal search intensity, which are equations (B.1), (B.2), and (B.3).

3. The wage functions satisfy the FOCs for the generalised Nash bargaining rule (equation (7)).

4. The government's budget constraint is satisfied each period (equation (1)).

5. The distribution of workers evolves according to the transition equations (C.1), (C.3), and (C.4), which are in Appendix C, consistent with the maximising behaviour of agents.

\subsection{Solving the Model}

In order to compute the market tightness in the model, economic agents must keep track of the distribution of workers over the productivity level, employment status, UI status, benefit level, and match quality $\left\{e_{i}(m), u_{i}^{U I}(\tilde{m}), u_{i}^{U U} ; i \in\right.$ $\{H, L\}, \forall m, \tilde{m}\}$ as they enter the vacancy creation condition (equation 6). To predict the next period's unemployment rate they need to know the inflow into and outflow from unemployment which are based on this distribution. I use the Krusell \& Smith (1998) algorithm to predict the laws of motion for both the insured and total unemployment rates as a function of current unemployment $(u)$ and aggregate productivity $(z)$. As the distributions of employed workers by match quality and insured unemployed workers by benefit level do not vary much over time, I use the stochastic steady state distributions ${ }^{16}$ and adjust for the em-

\footnotetext{
${ }^{16}$ Stochastic steady state distributions are obtained by simulating the economy over long periods and controlling for the aggregate productivity $(z)$ to be constant at its mean. For the distribu-
} 
ployment rate inferred from the state variables. I report the performance of this approximation in Appendix D.

\section{Calibration}

Before I calibrate the model to match the US economy, I specify the functional forms for the search cost functions, the distribution of the match quality, and the meeting function between workers and firms. I obtain a subset of the parameters using the simulated method of moments. The remaining parameters are taken from the empirical data and the literature. Table 3 summarises the pre-specified parameters and Table 5 describes the calibrated ones.

Functional forms The search cost function takes the following power function: $v_{j}(s)=a_{j} s^{1+d_{j}} ; j \in\{e, u\}$ where $a_{j}>0$ and $d_{j}>0$. I distinguish the search cost only between employment $(e)$ and unemployment $(u)$ to control for the relationship between the job-to-job transition rate and the job finding rate. ${ }^{17}$ Regarding the match quality distribution, a worker-firm match draws a new $m$ from the following Beta distribution: $F(m)=\underline{m}+\operatorname{betacdf}\left(m-\underline{m}, \beta_{1}, \beta_{2}\right)$ where $\beta_{1}>0$ and $\beta_{2}>0$, and $\underline{m}>0$ is the lowest match quality. The meeting function between unmatched firms and workers is similar to that in den Haan, Ramey, and Watson (2000) with the introduction of search intensity: $M(s, v)=\frac{s v}{\left(s^{l}+v^{l}\right)^{1 / l}} ; l>0$

Discretisation I discretise the aggregate productivity $(z)$ using Rouwenhurst (1995)'s method to approximate an AR(1) process with a finite-state Markov chain. For both $z$ and $F(m)$, I use 51 nodes when solving the model and 5,100 nodes by linear interpolation in the simulations. ${ }^{18}$ Finally, I use 101 equidistant nodes to approximate the unemployment rate between 0.02 to 0.2 .

Simulation I apply the calibrated model to the US economy by feeding in (1) productivity shocks that match the deviations of output (GDP per capita) from its HP trend and (2) the observed maximum UI durations during each recession. It is useful to note that the timing of each UI extension and how long it lasts are not predetermined but a result of the model's simulated unemployment series which can be used to measure how well the model can replicate the US labour market.

tion of the insured unemployed, I also separate between high and low unemployment states as UI extensions affect the shape of this distribution.

${ }^{17}$ Workers of type- $H$ and type- $L$ face the same cost of search and so do unemployed workers with and without UI.

${ }^{18}$ I define $f(m)$ as $F^{\prime}(m) / \sum_{m} F^{\prime}(m)$ where $F^{\prime}(m)$ is the probability density function of $F(m)$. 
Additionally, from May 2007, the Emergency Unemployment Compensation law has included the "Reachback Provision" providing UI eligibility to unemployed workers who have already exhausted their benefits prior to the extensions of UI. I simulate the model accordingly and study the impact of this programme in the results section.

\subsection{Pre-specified Parameters}

The pre-specified parameters are summarised in Tables 3 and 4. The model is monthly, and I assign the discount factor $\beta$ to be 0.9967 , implying an annual interest rate of 4\% which is the US average. Following Fujita and Ramey (2012), the vacancy creation cost $\kappa$ is set to be $0.0392 .{ }^{19} \mathrm{I}$ assign $\mu$, the worker's bargaining power, to be 0.5 following den Haan, Ramey and Watson (2000).

$\phi_{H}$ and $\phi_{L}$ are respectively the UI exhaustion rates during normal periods and recessions. I set $\phi_{H}$ to be $1 / 6$ which implies the standard maximum UI duration of 26 weeks given the monthly frequency. As for the UI extensions during recessions, I sort them into four main UI duration groups: (1) 39 weeks for January 1948 - December 1971, (2) 52 weeks for January 1972 - December 1974 and July 1982 - September 1991, (3) 68 weeks for January 1975 - June 1982 and October 1991 - July 2008, and (4) 90 weeks for August 2008 - June 2014. These four durations are obtained by averaging the observed maximum UI durations over the respective periods when UI was extended. The value $\phi_{L}$ changes and implies the maximum UI durations according to these UI duration regimes. ${ }^{20} \mathrm{I}$ set $\bar{u}$ to be $6.5 \%$ which historically has been used as a criterion in most UI extensions, albeit towards the upper end.

To determine the utility flow of type- $i$ unemployed workers, $h$ and, if insured, $b_{i}(m)$, I use the results in Gruber (1997). In particular, the drop in consumption for newly unemployed workers is $10 \%$ when receiving UI and $24 \%$ when not

\footnotetext{
${ }^{19}$ Using survey evidence on vacancy durations and hours spent on vacancy posting, Fujita and Ramey (2012) find the vacancy cost to be $17 \%$ of a 40 -hour-work week. Normalising the mean productivity to unity, this gives the value of 0.17 per week or 0.0392 per month. The actual mean productivity may be higher than (but not greatly different from) unity due to truncation from below of the match-specific quality.

${ }^{20}$ Note that these are the maximum UI durations used only when the unemployment rate is above the threshold $\bar{u}$. For example, in the simulation, the UI extension in the Great Recession is not triggered until April 2009.
} 
receiving UI given the replacement rate of 50\%. ${ }^{21}$ To find the implied $h$ and $b_{i}(m)$ given a set of parameters, I first guess the mean wages for the (type-i) employed with different match qualities $\left\{w^{0}(m), w_{i}^{0}(m) ; \forall m\right\}$ and set $h$ such that the average ratio of $h$ to $w^{0}(m)$ is 0.76 (where I use the steady state distribution of unemployed workers over match qualities to compute the weighted average). $b_{i}(m)$ is set such that the ratio of $h+b_{i}(m)$ to $w_{i}^{0}(m)$ is 0.9 for each match quality $m$. I then solve and simulate the model to check if the guess is close to its simulated counterpart. If it is not, I replace the guessed wages with the simulated ones and repeat until they are close enough. ${ }^{22}$

The slope of the unemployed's search cost function $a_{u}$ is normalised such that the search effort of the uninsured unemployed $s U U$ is unity when the economy is in the steady state, similar to Nagypál (2005). The power parameters in the search cost functions for both employed and unemployed workers $\left(d_{e}\right.$ and $\left.d_{u}\right)$ are set to unity in line with Christensen, Lentz, and Mortensen (2005) and Yashiv (2000) implying a quadratic search cost function. As these parameters are important for the elasticity of unemployment duration with respect to the maximum UI duration, I discuss in the next section how the results are comparable to the existing literature.

\subsection{Calibrated Parameters}

I use the simulated method of moments to assign values to the remaining twelve parameters $\left\{l, \delta, \lambda, \psi, \xi, a_{e}, \underline{m}, \beta_{1}, \beta_{2}, \rho_{z}, \sigma_{z}, \eta_{L}\right\}$ by matching main statistics in the US labour market and the labour productivity process during 1948-2007. ${ }^{23}$ The targeted moments are reported in Table 2 along with their empirical counter-

\footnotetext{
${ }^{21}$ Aguiar and Hurst (2005) report the drop in food consumption of workers upon becoming unemployed to be $5 \%$ and the drop in food expenditure to be $19 \%$. However, in their study, unemployed workers are not distinguished by their UI status which makes it impossible to separately identify $h$ and $b_{i}(m)$ 's under the present calibration strategy.

${ }^{22}$ It is useful to note that there is a benefit cap in the US which varies from state to state. The average maximum UI benefit is around USD 441 per week. Given a 50-percent replacement rate, this implies that anyone whose income is above the 58th percentile will face a cap on their UI benefits in the US. Since the benefit levels are calibrated to match the consumption drops for newly unemployed workers, these benefits levels are in fact always smaller than half of the labour income at the 58th percentile in my model. Specifically, the maximum UI benefit payment in the model is 0.3 whereas the 58th percentile of the labour income is 0.73 implying a benefit cap at 0.36 with a 50 -percent replacement rate.

${ }^{23}$ The transition rates are author's own calculations based on the CPS data. For output, I use the quarterly real GDP series provided by the Bureau of Economic Analysis (BEA), and I use the BLS quarterly series for non-farm output per job to represent the labour productivity.
} 
parts. Table 6 shows other related moments not targeted in the calibration. The values of calibrated parameters are in Table 5.

For targeted moments, the baseline model matches the twelve targeted moments quite well overall. However, the insured unemployment rate is slightly higher, and the job finding rate is more volatile than in the data. For non-targeted moments, the model matches the dynamics of unemployment grouped in four duration bins quite well in terms of the first and second moments. However, the model could further improve on the volatility of vacancies and the correlation between unemployment and vacancies. ${ }^{24}$

\section{Results}

The results in this section are based on the aggregate productivity series that matches the deviations of output from its HP trend as depicted in Figure $4 .^{25}$

\subsection{Performance}

UI Extensions Figure 5 shows that the model is successful in generating realistic UI extensions in terms of both when they are triggered and how long each extension lasts. This is due to how well the model replicates the US unemployment series (of which UI extensions are a function) as shown in Figure 6. The model does exceptionally well in capturing the dynamics of unemployment during the Great Recession. The series noticeably overshoots in the early 2000s. I address this issue in the last part of this subsection by correcting for the state-level implementation of UI extensions.

Long-term Unemployment Figure 7 shows that the model can account for a large fraction of the observed rise in long-term unemployment in the Great Recession, but it tends to overshoot and does not produce enough persistence in certain recessions. The main reason for this is due to the sudden change in the optimal job search behaviour of insured unemployed workers when a UI extension is terminated, a mechanism that I will discuss in the next subsection.

\footnotetext{
${ }^{24}$ The main reason why vacancies are not as volatile as they are in the data is due to the endogenous separation margin. In recessions, unemployment increases at a faster rate from endogenous match separations which makes vacancy posting less costly, and this counteracts with the effect of negative aggregate shocks.

${ }^{25}$ We can see that the drop in aggregate productivity during the Great Recession is neither of larger magnitude nor does it exhibit more persistence than in previous recessions.
} 
Distribution of Unemployment Duration Figure 8 shows that the model produces a substantial rise in the average unemployment duration in the Great Recession, but, similar to long-term unemployment, it generates little persistence once compared to the data. It does very well in producing a realistic shift in the distribution of unemployment duration towards longer duration bins. In Figure 9, I plot the distributions in December 2007 and June 2010, where UI was only extended in the latter case. ${ }^{26}$ With respect to the entire 1948-2014 period, I show in Figure 10 the shares of unemployment by four duration bins (less than 1 month, 2-3 months, 4-6 months, and longer than 6 months). These figures suggest that the model is suitable for studying the dynamics of the entire distribution of unemployment duration and not just the long-term unemployment dynamics.

Job Findings In the left panel of Figure 11, I compare the model's job finding rate with the empirical series. Despite a clear negative trend that the model does not feature, it produces a fall in the job finding rate during the Great Recession similar in magnitude to that in the data. When I condition on the UI status of workers as displayed in the right panel of same figure, we can see that (1) the job finding rate of the insured unemployed workers is lower and falls more dramatically than that of the uninsured during the Great Recession. Both features are consistent with findings from the empirical section.

State-level Implementation of UI Extensions In the US, implementations of UI extensions are at the state level. Therefore, it is possible that the maximum potential UI duration announced at the federal level does not coincide with the average maximum potential UI duration implemented across states, especially when only few states implement UI extensions. This is exactly the case in the early 2000 recession where only 5 states implemented UI extensions making the average maximum potential UI duration to be 30 weeks shorter than the federally announced maximum duration. This stark difference affects the model's results significantly. Figure 12 shows that, for the 2000 recession, total unemployment no longer overshoots (if anything, slightly undershoots) when the average UI duration is used in the simulation. As a result, UI extension is not triggered, and thus long-term unemployment is only mildly affected.

That said, the results for the Great Recession are robust to using the crossstate average of maximum UI duration since 49 states actually implemented the

\footnotetext{
${ }^{26}$ I choose June 2010 because it is when the model's long-term unemployment rate reaches its peak. Additionally, the model generates a hump in the distribution in 2010 similar to the empirical distribution owing to the endogenous separation margin.
} 
extensions, and therefore the federally announced maximum UI duration is just 5 weeks longer than the average across states. Unfortunately, the state-level UI implementation data can be obtained from only 1999. However, as the focus of the paper is on the Great Recession, all the results during this episode are computed based on the actual implementation of UI extensions across states. ${ }^{27}$

\subsection{Mechanisms}

Job Search Behaviour The optimal job search behaviour of workers respond to UI extensions in the following ways: (1) only the search intensity of insured unemployed workers varies with the maximum UI duration, and (2) the higher the benefit level the lower the search effort is exerted, and such behaviour is more pronounced when the extended UI duration is longer.

Figure 13's top left panel shows that the conditional job finding rate of the insured unemployed workers drops when UI is extended (implied by $u \geq \bar{u}=6.5 \%$ ) whilst the rates for the employed and uninsured unemployed are largely constant. Figure 13's top right panel shows that, amongst the insured unemployed, job search effort decreases in the amount of benefit. In terms of worker heterogeneity, higher productivity workers exert slightly more search effort as their value during employment is relatively higher than the lower productivity type. The job finding rates between the two productivity types during 1948-2014 are quite similar. However, when considering different UI statuses, the job finding rate of the insured unemployed is smaller and exhibits higher volatility. This suggests that once we condition on the UI status, workers' productivity types contribute little to the rise of long-term unemployment and unemployment duration. Job findings are driven not only by the job search behaviour but also by the decision between a worker and a firm to form a match once they meet. Such decisions along with match separation decisions are also affected by the endogenous UI extensions as I discuss next.

Match Formation/Separation We know that the worker's surplus from being employed and the value of a producing firm $\left(W S_{i}^{j}(m ; \omega)\right.$ and $J_{i}^{j}(m ; \omega) ; j \in$ $\{e(\tilde{m}), U I(\tilde{m}), U U\})$ are simply a constant fraction of a total match surplus $\left(\mu S_{i}^{j}(m ; \omega)\right.$ and $(1-\mu) S_{i}^{j}(m ; \omega)$ respectively). Therefore, both workers and firms always agree when a match should be formed (when $S_{i}^{j}(m ; \omega)>0$ ) and when it should be

\footnotetext{
${ }^{27}$ More availability of the state-level UI implementation data would be useful in potentially explaining the overshooting of the long-term unemployment series.
} 
separated (when $\left.S_{i}^{j}(m ; \omega)<0\right)$. A match surplus when a worker is currently employed, $S_{i}^{e(\tilde{m})}(m ; \omega)$, determines endogenous match separations whereas a match surplus when a worker is currently unemployed, either $S_{i}^{U I(\tilde{m})}(m ; \omega)$ or $S_{i}^{U U}(m ; \omega)$, determines how many matches will be formed, given that unemployed workers and firms have met.

Figure 13's bottom left panel shows that total match surpluses for employed and insured unemployed workers, $S_{i}^{e(\tilde{m})}(m ; \omega)$ and $S_{i}^{U I(\tilde{m})}(m ; \omega)$, decrease in unemployment, and they decrease at a faster rate when UI is extended $(u \geq \bar{u}){ }^{28}$ The longer the extended duration, the more drastic is the drop in the match surplus. Further, $S_{i}^{U I(\tilde{m})}(m ; \omega)$ decreases in $\tilde{m}$ in Figure 13's bottom right panel. A higher $\tilde{m}$ implies a higher outside option of the insured unemployed, $h+b_{i}(\tilde{m})$, meaning that a match is less likely to be formed. ${ }^{29}$ A similar argument applies to $S_{i}^{e(\tilde{m})}(m ; \omega)$ but, instead, on the job separation margin where $h+b_{i}(\tilde{m})$ is the outside option of an employed worker if she quits and is eligible for UI. ${ }^{30}$

What Drives (Long-term) Unemployment? I study the contribution of 3 UI channels (job search behaviour, match formation and job separation) on unemployment and its duration during the Great Recession by fixing/shutting down one channel at a time (assuming that a given channel does not respond to UI extensions). ${ }^{31}$ I find that long-term unemployment is largely unaffected by the response of match formation and dissolution but it falls drastically (over 3pp) when the job search channel is shut down as shown in Figure 14. Despite a small impact on long-term unemployment, the job separation margin is most important in driving total unemployment. ${ }^{32}$

\footnotetext{
${ }^{28}$ It can be seen that the match surplus for the uninsured unemployed workers is higher when the UI extension is longer. This is because it is actually better for the uninsured unemployed to regain employment and potentially qualify for UI benefits.

${ }^{29} m$ instead increases $S_{i}^{U I(\tilde{m})}(m ; \omega)$ because a higher match quality in the production raises the firm's profit and the worker's wage and potential UI benefit after being employed with $m$.

${ }^{30}$ In the simulation, the success rate of worker-firm meetings is, despite procyclical, always very close to one. The reasons are (1) for insured workers, those likely to have an unproductive meeting have currently high UI benefits, and it is unlikely for them to meet a firm in the first place, and (2) for uninsured workers, the surplus from working is very high due to their lower outside option which means the meetings are likely to lead to viable matches.

${ }^{31}$ Note that the path of aggregate shocks $(z)$ is as in the baseline model (Figure 4). I shut down a channel by setting the unemployment rate used in the respective policy function to be at the pre-Great Recession level which is less than $\bar{u}$ implying that $\mathrm{UI}$ is not extended.

${ }^{32}$ I also study the contribution of vacancy creation on long-term unemployment. However, its effect is small because the volatility of vacancies in the model is rather low relative to the data.
} 


\subsection{Policy Experiment}

In this counterfactual exercise, I eliminate all UI extensions during the Great Recession (by increasing the UI exhaustion rate, $\phi(u)$, to $\phi_{L}$ implying a shorter maximum UI duration of 26 weeks) and quantify their effects on unemployment and its duration structure given the same path of aggregate productivity shocks $(z)$ as in the baseline model (Figure 4). I compute both the microeconomic and general equilibrium effects of UI. The former features only the higher UI exhaustion rate and the response of job search behaviour to the shorter UI duration, and it is comparable to results from the existing literature. The latter considers also the responses of match separations and match formations to the shorter UI duration. ${ }^{33}$ Table 7 summarises the results from this experiment.

Long-term unemployment The removal of UI extension has a large impact on long-term unemployment even when workers and firms do not react to this change. This is not surprising because, given the standard UI duration (of 26 weeks), all long-term unemployed workers are uninsured by definition, and uninsured unemployed workers have a much higher job finding rate than do insured unemployed workers. As a result, by removing all UI extensions during the Great Recession, the peak of long-term unemployment falls drastically from 4.7 percent in the baseline model to 1 percent when workers and firms do not react to the shorter maximum UI duration (as shown in Table 7). ${ }^{34}$

Unemployment Total unemployment is less affected by the removal of UI extensions than long-term unemployment. The impact of increasing the UI exhaustion rate is a slight fall of less than $1 \mathrm{pp}$ in the unemployment rate (measured at its peak) as shown in Table 7. When the job search behaviour responds to the extension removal, the peak falls by $1.8 \mathrm{pp}$. It is only in the general equilibrium context, where match separation decisions also react to the extension removal, that the peak of the unemployment rate falls by $2.9 \mathrm{pp}$.

The microeconomic effect of UI on total unemployment is more subdued is because it concerns only a subgroup of unemployed workers (namely, those with

\footnotetext{
${ }^{33}$ It is clear from the previous decomposition exercise that the response of match formation to UI extensions is negligible.

${ }^{34}$ It is useful to note that the large microeconomic effect of UI on long-term unemployment relies on the higher job finding rate of uninsured unemployed workers when compared to the insured. By incorporating genuine duration dependence in the job finding rate, the UI effect could become smaller since unemployed workers who recently exhausted UI cannot increase their job finding rate as much as in the baseline model. Therefore, the insured unemployment state is less desirable and there will be fewer insured unemployed workers during UI extensions.
} 
UI), whilst for the general equilibrium effect, the match separation margin applies to all employed workers and determines the inflow of (insured) unemployed workers. This same argument also explains why the micro effect of UI on longterm unemployment is large.

This result is consistent with the existing literature on the effects of UI extensions on unemployment in the Great Recession. Most of the studies focus on the micro effect where the worker-firm relationships are not taken into account and find that the unemployment rate would have been 0.1-1.8pp lower had there been no UI extensions. This is in line with the micro effect of UI extensions previously discussed. The larger general equilibrium effect of UI extensions in this model is similar to findings in Hagedorn et al. (2019), but they focus the impact on vacancy creation whilst mine comes from job separations. ${ }^{35}$ Lastly, the unemployment rate is much less persistent when there is no UI extensions, i.e. there would be no jobless recoveries. This result is consistent with the findings in Mitman and Rabinovich (2014).

Non-linearity of UI effects In Table 7, I also report the effects of removing UI extensions during the early 1990s recession (equivalent of cutting 42 weeks of UI duration). There is a non-linearity of the UI effects on all variables considered. For example, a one-week reduction of UI duration reduces an average unemployment duration by 0.3 weeks during the 1990s recession ${ }^{36}$ but for the Great Recession this number is 0.4 weeks. This is mainly due to the different paths of shocks that hit the economy. As can be seen in Figure 4, the Great Recession features a larger but less persistent negative shock comparing to the early 1990s recession. This suggests that the unemployment cost of UI extension is less pronounced when a recession is more persistent (e.g. the early 1990s) since it is more difficult for workers to find a job regardless of the maximum UI duration.

\subsection{Reachback Provision Programme}

From May 2007, the Emergency Unemployment Compensation law has included the "Reachback Provision" providing UI eligibility to unemployed workers who have already exhausted their benefits prior to the UI extensions. This

\footnotetext{
${ }^{35}$ Figure 15 shows that indeed the empirical job separation rate was particularly high during the Great Recession when compared to other recessions.

${ }^{36}$ If we only consider the micro effect of UI extensions, this number is around 0.26 for the 1990s recession which is still higher than the existing empirical findings of around 0.1-0.2. See, for example, Katz and Meyer (1990), Moffitt (1985), and Moffitt and Nicholson (1982).
} 
programme can potentially affect long-term unemployment since it is targeted directly at this group of workers. As the programme is already incorporated in the baseline case, I can measure its effect by removing the programme and leaving everything else the same. The results are summarised in Table 8. I find that Reachback Provision does not have a significant impact on the aggregate labour market. The (long-term) unemployment rate is only $0.1 \mathrm{pp}$ smaller than in the baseline model. The small effect is explained by the fact that the subgroup of workers who are affected by the programme represents just $3.5 \%$ of the unemployment population. However, from the CPS data, the true effect of this programme could be non-trivial since unemployed workers who already exhausted UI represented a substantial 44\% of the long-term unemployed in January 2008. The model produces a much smaller number for this group of workers because once the insured unemployed exhaust their benefits, they adopt the job search behaviour of the uninsured which implies a much higher unemployment exit rate than the insured.

\subsection{Rational Expectations}

As a high unemployment rate triggers UI extensions, agents can form expectations about future unemployment to gauge the probability that a UI extension occurs or terminates. To quantify the importance of rational expectations about the timing of UI extensions, I compare the baseline results to an alternative scenario where UI extensions (and how long they last) are completely unexpected to the agents. This is the 'adaptive expectations' in Mitman and Rabinovich (2014) where agents assume the maximum UI duration to remain the same until they observe otherwise. This new UI duration policy is just a constant instead of a function of unemployment, i.e. $\phi$ instead of $\phi(u)$. When UI extensions are assumed to last forever, the UI effects are expected to be more drastic because (1) the insured unemployed will lower search effort, (2) matches are less likely to be formed, and (3) matches are more likely to separate. I find that disregarding rational expectations about the timing of UI extensions leads to a significant overestimation of both total and long-term unemployment by over $2 \mathrm{pp}$ at the peak of the Great Recession and an overestimation of average unemployment duration by almost 4 weeks as shown in Table 8 . Therefore, it is vital that rational expectations are taken into account when studying the effects of UI extensions in general equilibrium. 


\subsection{On-the-job Search}

In this exercise, I show how on-the-job search contributes to unemployment and its duration distribution during the Great Recession. On the one hand, onthe-job search allows employed workers to improve their match qualities and the associated UI benefits if they become insured unemployed. Since the job search effort and job finding rates are decreasing in the benefit level, this would increase unemployment and its duration. On the other hand, on-the-job search increases the value of being employed. Therefore, more unemployed workers would be induced to take up job offers even when the first match quality draws are not great (since they can search on the job and leave their current matches with not so great match qualities) and spend less time in unemployment. The last column of Table 8 shows the main results when on-the-job search is not allowed. I find that, during the Great Recession when UI is extended, on-the-job search contributes to a small but significant increase in (long-term) unemployment of up to (0.4) $0.5 \mathrm{pp}$ from the baseline model as well as a 1-week increase in the average unemployment duration. On-the-job search, however, has a negligible impact outside recessionary periods.

\subsection{Hazard Rate of Exiting Unemployment}

Due to the heterogeneity in job finding rates amongst unemployed workers, the model generates the negative duration dependence in the unemployment exit rate that comes purely from the changing composition in the stocks of unemployment. ${ }^{37}$ At longer unemployment durations, the stocks of unemployment are more represented by those with lower exit rates (the insured unemployed with higher UI benefits in this case). Moreover, the strength of the duration dependence is positively correlated with the state of the economy as pointed out in Wiczer (2015). Figure 16 shows the hazard rates of exiting unemployment for December 2007 (maximum 26 weeks of UI) and June 2010 (maximum 90 weeks of UI). The negative duration dependence is more severe with and persists as long as the UI extensions themselves. Empirical results based on Kroft et al. (2016) and Wiczer (2015) suggest that the hazard rate is stable after 6 months of being unemployed. In the model, however, since uninsured unemployed workers exit

\footnotetext{
${ }^{37}$ The duration-dependent unemployment exit rate is a featured result in several studies including Clark and Summers (1979), Machin and Manning (1999), and Elsby, Hobijn, Şahin and Valletta (2011).
} 
unemployment at a faster rate than do the insured, the hazard rate rises upon the exhaustion of UI benefits. ${ }^{38}$

To study the role of unobserved heterogeneity, I estimated the same non-linear state space model in Ahn and Hamilton (2019). They find that the unobserved heterogeneity of workers (in terms of unemployment exit rate) contribute to the rise in unemployment duration during the Great Recession. I can relate their interpretation of unobserved heterogeneity to the UI status in my model as the insured unemployed have a lower unemployment exit rate than the uninsured. I find little differences in the unemployment exit rate based on the heterogeneous worker productivity. I describe in full the state space model, the estimation and the results in Appendix E and F.

\section{Conclusion}

This paper quantifies the impact of endogenous UI extensions on the dynamics of unemployment and its duration structure which have an important implication on the recovery of the aggregate labour market. I develop a general equilibrium search and matching model where the maximum UI duration depends on the unemployment rate, and the UI benefits depend on the match quality during employment. Workers are heterogeneous and their job search effort depend on their characteristics as well as the maximum UI duration.

I find that the generous UI extensions during the Great Recession contribute to $10-30 \%$ of the rise of unemployment. Both the microeconomic and general equilibrium effects of UI are important and the former is consistent with existing empirical estimates. The UI effect on long-term unemployment is, however, much larger as it contributes up to $90 \%$ of its rise where the microeconomic effect of UI is most responsible. That said, the UI effect is non-linear as its magnitude is smaller in the early 1990s recession. I also show that disregarding rational expectations about the timings of UI extensions implies a significant overestimation of the UI effects on unemployment and its duration.

\footnotetext{
${ }^{38}$ The heterogeneity in worker productivity could potentially explain the negative duration dependence after the UI exhaustion since type- $H$ workers exit unemployment at a faster rate. However, despite this heterogeneity, the exit rates of both types $(H$ and $L)$ when uninsured are similar and much higher than when insured which leaves the average exit rate after UI exhaustion rather stable. In order to fit the empirical results better, other heterogeneity amongst uninsured unemployed workers could be introduced such as different values of home production, or even a larger degree of heterogeneity in productivity.
} 


\section{References}

[1] Aaronson, Daniel, Bhashkar Mazumder, and Shani Schechter, 2010. "What is behind the rise in long-term unemployment?", Economic Perspectives, QII, pp. 28-51.

[2] Abraham, Katharine G., John C. Haltiwanger, L. Kristin Sandusky, and James R. Spletzer, 2016. "The Consequences of Long Term Unemployment: Evidence from Matched Employer-Employee Data”, IZA Discussion Papers, no. 10223.

[3] Aguiar, Mark and Erik Hurst, 2005. "Consumption versus Expenditure", Journal of Political Economy, 113, pp. 919-948.

[4] Ahn, Hie Joo, 2016. "The Role of Observed and Unobserved Heterogeneity in the Duration of Unemployment Spells", https://sites.google.com/site/hiejooahn/research.

[5] Ahn, Hie Joo and James D. Hamilton, 2019. "Heterogeneity and Unemployment Dynamics", Journal of Business \& Economic Statistics, DOI: 10.1080/07350015.2018.1530116.

[6] Barnichon, Regis and Andrew Figura, 2014. "The Effects of Unemployment Benefits on Unemployment and Labor Force Participation: Evidence from 35 Years of Benefits Extensions", Finance and Economics Discussion Series 2014, no. 65, Board of Governors of the Federal Reserve System (US).

[7] Card, David, Phillip B. Levine, 2000. "Extended benefits and the duration of UI spells: evidence from the new Jersey extended benefit program", Journal of Public Economics, 78 (1-2), pp. 107-138.

[8] Carrillo-Tudela, Carlos and Ludo Visschers, 2014. "Unemployment and Endogenous Reallocation over the Business Cycle", https://sites.google.com/site/ludosresearch/.

[9] Clark, Kim B. and Lawrence H. Summers, 1979. "Labor Market Dynamics and Unemployment: A Reconsideration”, Brookings Papers on Economic Activity, 10, 13-72.

[10] Christensen, Bent J., Rasmus Lentz, Dale T. Mortensen, George R. Neumann, and Axel Werwatz, 2005. "On-the-job search and the wage distribution", Journal of Labor Economics, 23(1), pp. 31-58.

[11] den Haan, Wouter J., Garey Ramey and Joel Watson, 2000. "Job Destruction and Propagation of Shocks", American Economic Review, 90(3), pp. 482498.

[12] Elsby, Michael W. L., Bart Hobijn, Ayşegül Şahin and Robert G. Valletta, 2011. "The Labor Market in the Great Recession-An Update to September 2011”, Brookings Papers on Economic Activity, 2011(2), pp. 353-384.

[13] Faig, Miguel, Min Zhang and Shiny Zhang, 2016. "Effects of Extended Unemployment Benefits on Labor Dynamics", Macroeconomic Dynamics, 20(05), pp. 1174-1195.

[14] Farber, Henry S. and Robert G. Valletta, 2013. "Do Extended Unemploy- 
ment Benefits Lengthen Unemployment Spells? Evidence from Recent Cycles in the U.S. Labor Market", NBER Working Papers, no. 19048.

[15] Fredriksson, Peter and Bertil Holmlund, 2001. "Optimal Unemployment Insurance in Search Equilibrium", Journal of Labor Economics, 19(2), pp. 370-399.

[16] Fujita, Shigeru and Garey Ramey, 2012. "Exogenous versus Endogenous Separation”, American Economic Journal: Macroeconomics, 4(4), pp. 6893.

[17] Fujita, Shigeru, 2010. "Effects of the UI Benefit Extensions: Evidence from the CPS", Federal Reserve Bank of Philadelphia Working Paper, No. 1035/R.

[18] Fujita, Shigeru and Giuseppe Moscarini, 2015. "Recall and unemployment", Federal Reserve Bank of Philadelphia Working Paper, No. 14-3.

[19] Gruber, Jonathan, 1997. "The Consumption Smoothing Benefits of Unemployment Insurance", American Economic Review, 87(1), pp. 192-205.

[20] Hagedorn, Marcus, Fatih Karahan, Iourii Manovskii, and Kurt Mitman, 2019, "Unemployment Benefits and Unemployment in the Great Recession: The Role of Macro Effects", https://www.sas.upenn.edu/ manovski/research.html.

[21] Hornstein, Andreas, 2012. "Accounting for Unemployment: The Long and Short of It", Federal Reserve Bank of Richmond Working Paper, no. 12-07.

[22] Katz, Lawrence F. and Bruce D. Meyer, 1990. "The impact of the potential duration of unemployment benefits on the duration of unemployment", Journal of Public Economics, 41(1), pp. 45-72.

[23] Kroft, Kory, Fabian Lange, Matthew J. Notowidigdo and Lawrence F. Katz, 2016. "Long-Term Unemployment and the Great Recession: The Role of Composition, Duration Dependence, and Non-Participation", Journal of Labor Economics, 34, no. S1 (Part 2, January 2016): S7-S54.

[24] Krause, Michael and Thomas A. Lubik, 2010. "On-the-job search and the cyclical dynamics of the labor market", Federal Reserve Bank of Richmond Working Paper, no. 10-12.

[25] Krueger, Alan B. and Andreas Mueller, 2010. "Job search and unemployment insurance: new evidence from time use data", Journal of Public Economics, 94(3-4), pp. 298-307.

[26] Krueger, Alan B. and Andreas Mueller, 2011. "Job search, emotional wellbeing and job finding in a period of mass unemployment: evidence from high frequency longitudinal data", Brookings Papers on Economic Activity, 42, pp. 1-81.

[27] Krusell, Per and Anthony A. Smith Jr., 1998. "Income and wealth heterogeneity in the macroeconomy", Journal of Political Economy, 106, pp. 867896.

[28] Machin, Steve and Alan Manning, 1999. "The causes and consequences of longterm unemployment in Europe". In O. Ashenfelter and D. Card (Ed.), 
Handbook of Labor Economics. Handbooks in economics, 3C(5). Elsevier B.V, Amsterdam, Holland, pp. 3085-3139.

[29] Mazumder, Bhashkar, 2011. "How did unemployment insurance extensions affect the unemployment rate in 2008-10?", Chicago Fed Letter, no. 285.

[30] Meyer, Bruce D., 1990. "Unemployment insurance and unemployment spells", Econometrica, 58(4), pp. 757-782.

[31] Mitman, Kurt and Stanislav Rabinovich, 2014. "Do Unemployment Benefits Explain the Emergence of Jobless Recoveries?", http://www.kurtmitman.com.

[32] Moffitt, Robert, 1985. "Unemployment insurance and the distribution of unemployment spells”. Journal of Econometrics, 28(1), pp. 85-101.

[33] Moffitt, Robert, Nicholson, Walter, 1982. "The effect of unemployment insurance on unemployment: the case of federal supplemental benefits", $R e$ view of Economics and Statistics, 64(1), pp. 1-11.

[34] Mortensen, Dale T. and Christopher A. Pissarides, 1994. "Job Creation and Job Destruction in the Theory of Unemployment", Review of Economic Studies, 61(3), pp. 397-415.

[35] Nakajima, Makoto, 2012. "A quantitative analysis of unemployment benefit extensions", Journal of Monetary Economics, 59(7), pp. 686-702.

[36] Nagypál, Éva, 2005. "On the extent of job-to-job transitions", http://faculty.wcas.northwestern.edu/ een461/research.html.

[37] Ravn, Morten O. and Vincent Sterk, 2017. "Job Uncertainty and Deep Recessions", Journal of Monetary Economics, 57 (2), pp. 217-225.

[38] Rothstein, Jesse, 2011. "Unemployment Insurance and Job Search in the Great Recession”, NBER Working Papers, no. 17534.

[39] Rouwenhorst, K. Geert, 1995. "Asset pricing implications of equilibrium business cycle models". In: Cooley, T. F. (Ed.), Frontiers of Business Cycle Research. Princeton University Press, Princeton, NJ, pp. 294-330

[40] Rujiwattanapong, W. Similan, 2017. "Unemployment Insurance and Labour Productivity over the Business Cycle", https://sites.google.com/site/wsrujiwattanapong/home/research.

[41] Shimer, Robert, 2006. "On-the-job search and strategic bargaining", European Economic Review, 50(4), pp. 811-830.

[42] Valletta, Robert G., and Katherine Kuang, 2010. "Extended unemployment and UI benefits", Federal Reserve Bank of San Francisco Economic Letter, no. 2010-12.

[43] Wiczer, David, 2015. "Long-Term Unemployment: Attached and Mismatched?", Federal Reserve Bank of St. Louis Working Papers, no. 2015-42.

[44] Yashiv, Eran, 2000. "The Determinants of Equilibrium Unemployment", American Economic Review, 90(5), pp. 1297-1322. 
Figure 1: Unemployment and Long-term Unemployment (those unemployed $>6$ months) in the US (Source: CPS)

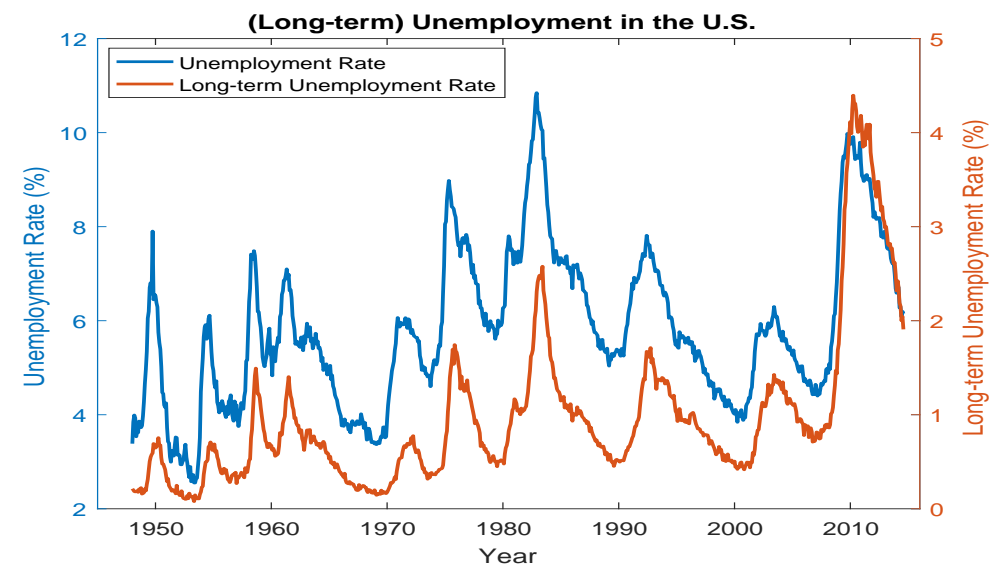

Figure 2: Maximum Unemployment Insurance Duration (weeks) in the US (Source: ETA. Shaded areas denote the recessions. Dashed green line denotes the automatic extensions)

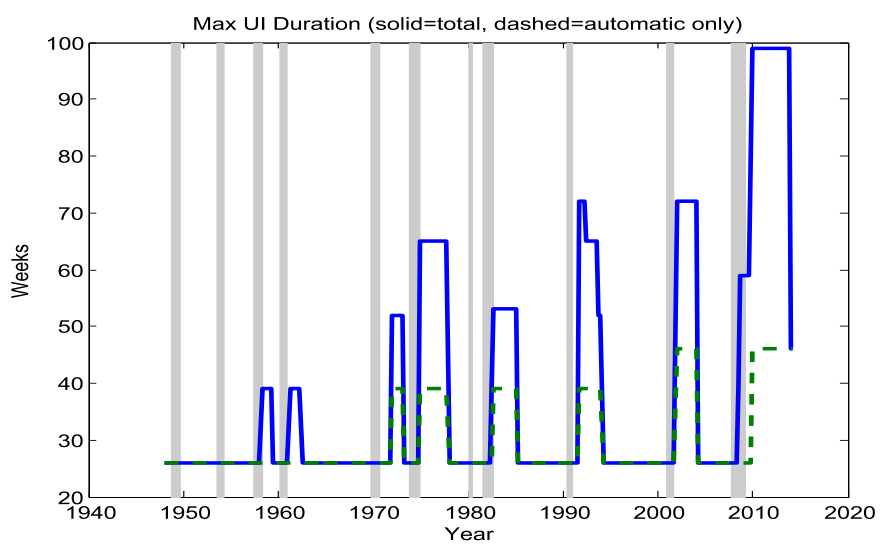

Figure 3: Shares (\%) of Current UI Recipients in 2 Subgroups: Long-term Unemployment and Newly Unemployed Workers (Source: CPS)

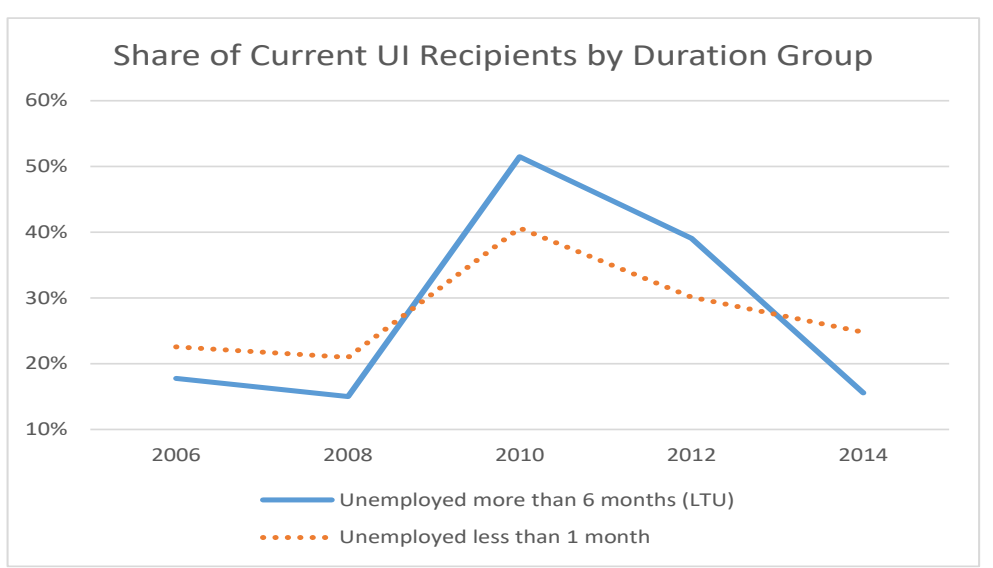


Figure 4: Aggregate Productivity Series ( $z$ ) as Constructed to Match Output Deviations from HP Trend

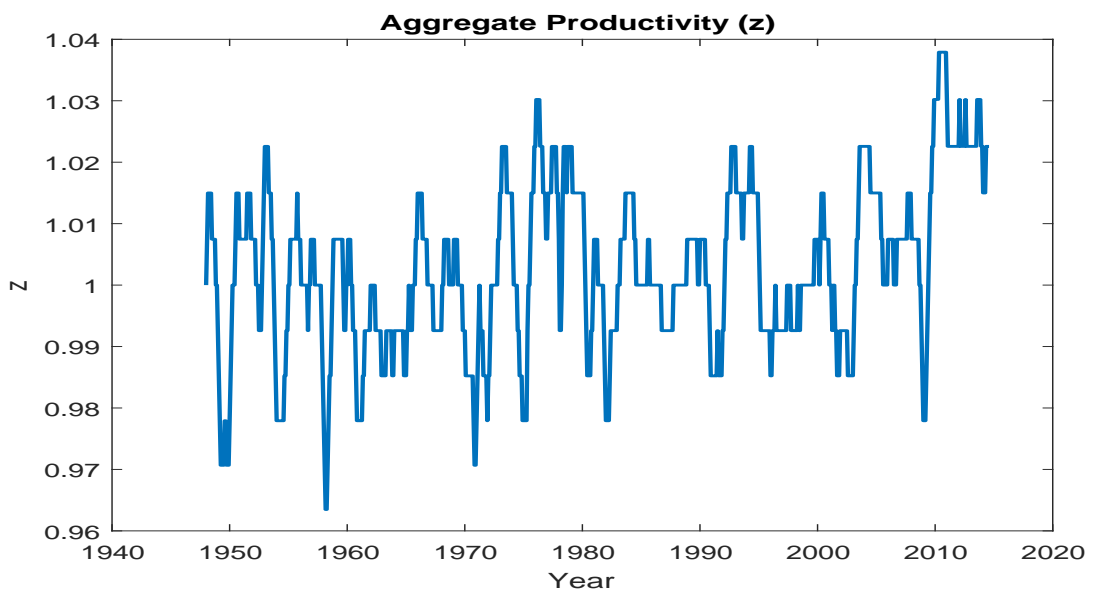

Figure 5: UI Extensions from the Model and the Data (Data source: ETA)

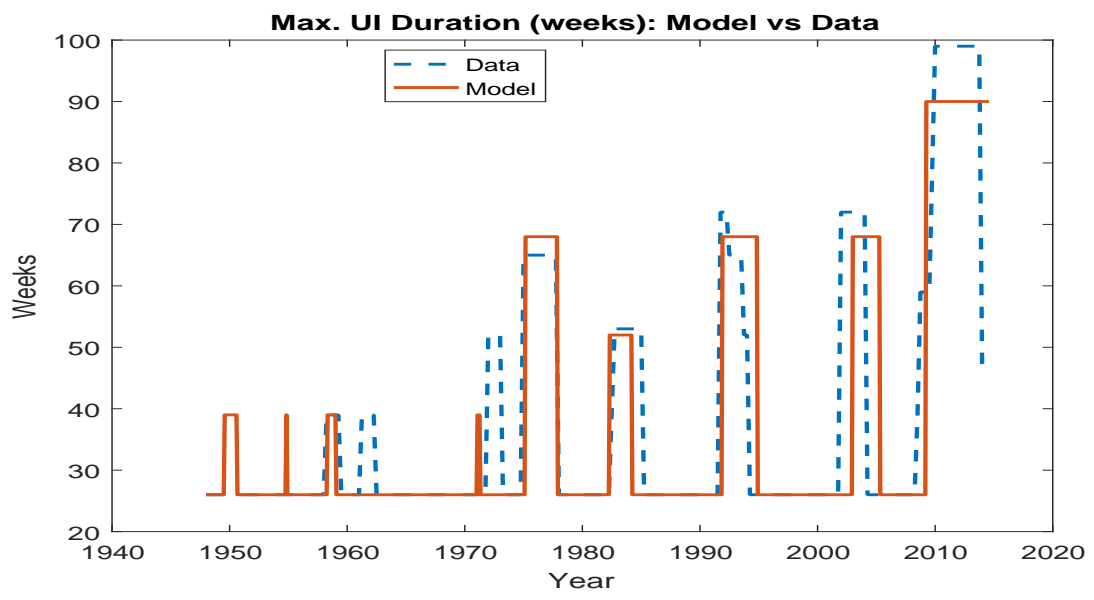

Figure 6: Unemployment Rate (\%): Model and Data (Data source: CPS)

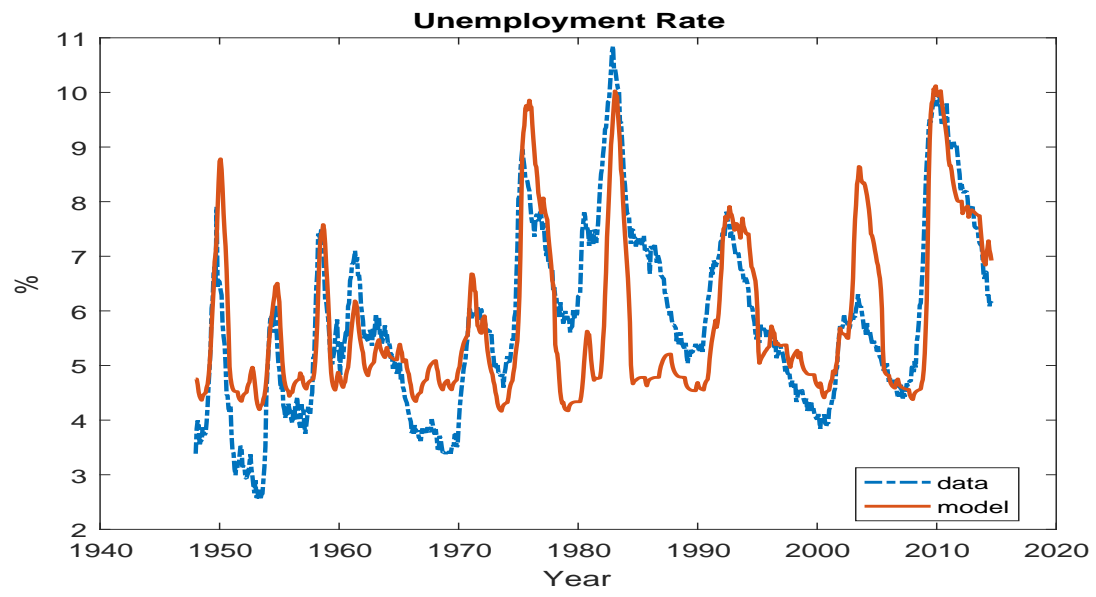


Figure 7: Long-term Unemployment Rate (\%): Model and Data (Data source: CPS)

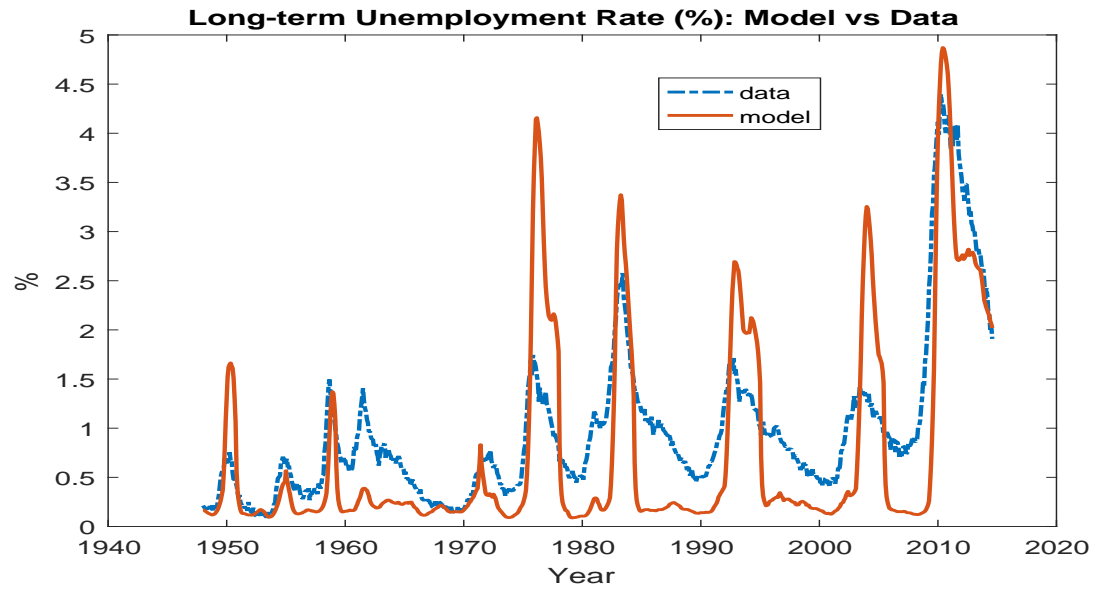

Figure 8: Average Unemployment Duration: Model and Data (Data source: CPS)

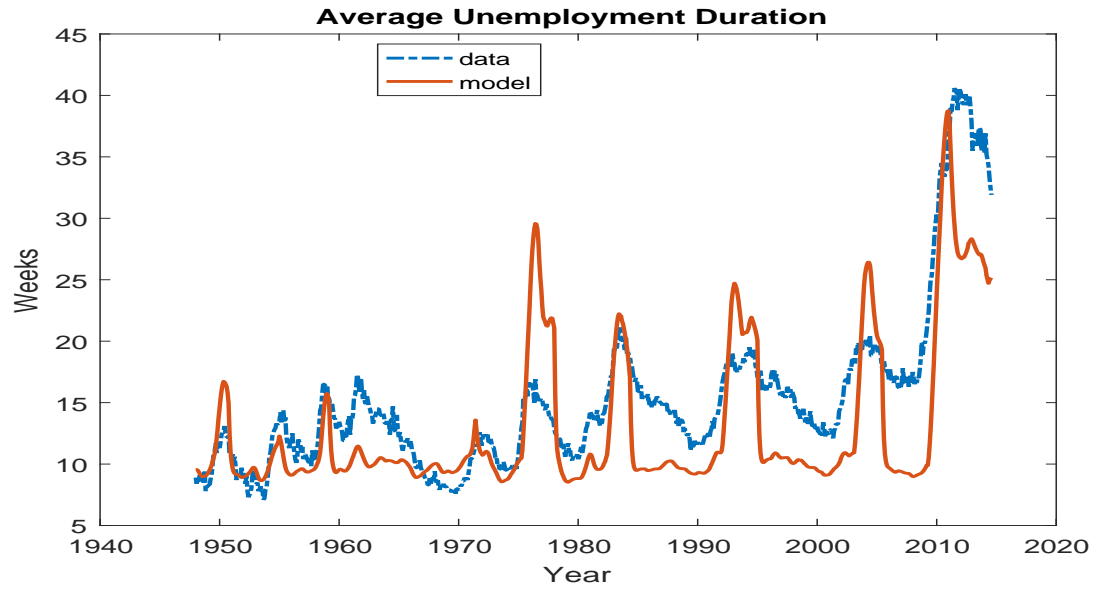

Figure 9: Distribution of Unemployment Durations during the Great Recession (Data source: CPS)
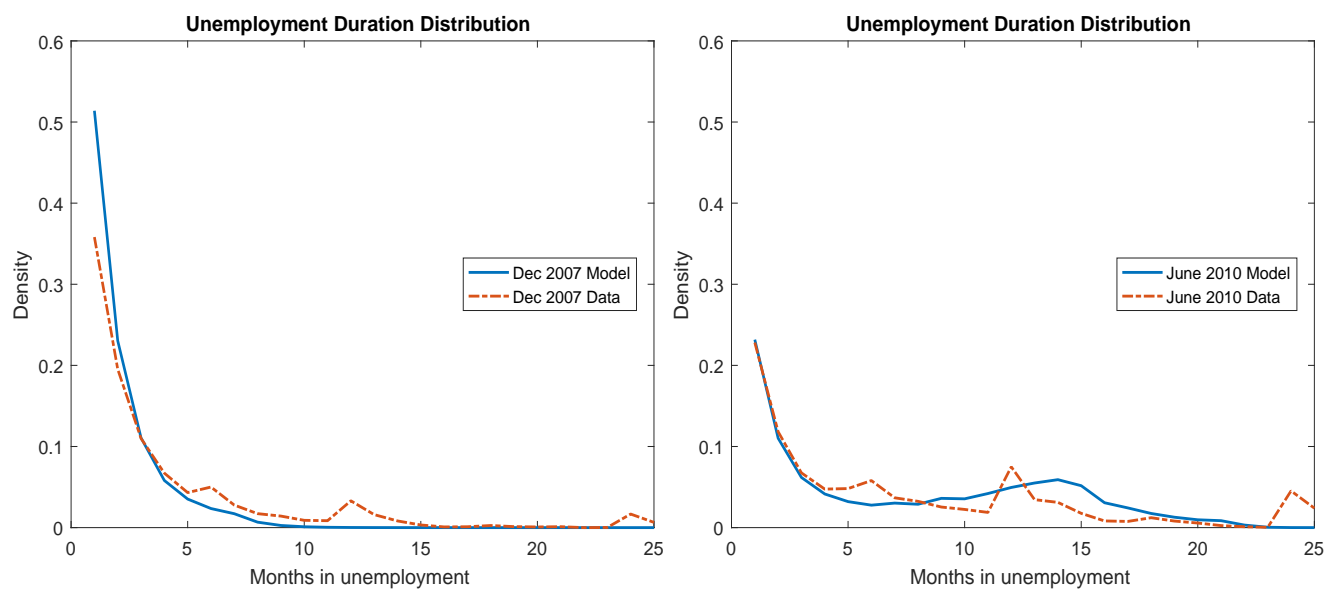
Figure 10: Unemployment Shares (\%) by Durations (Data source: CPS)
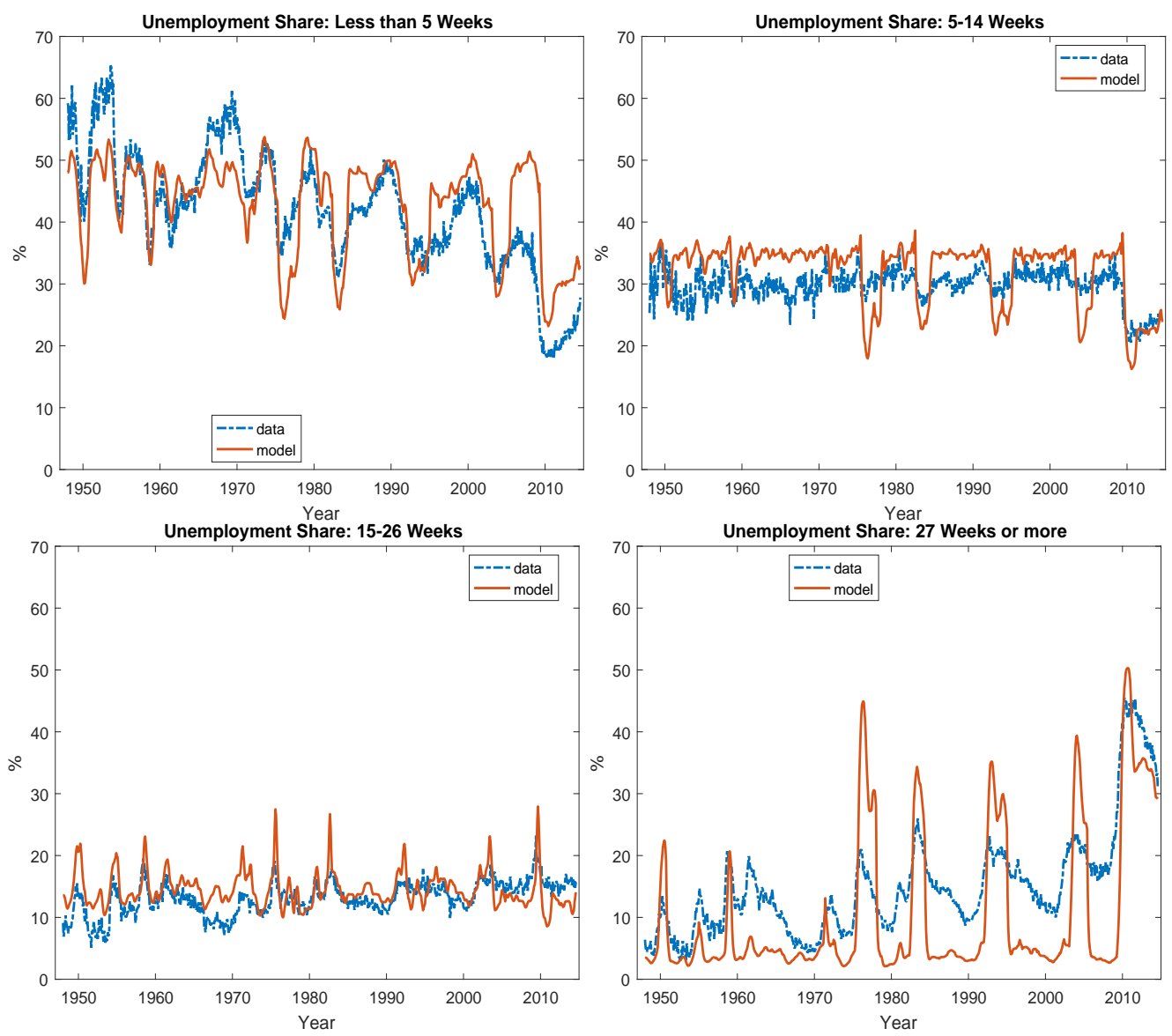

Figure 11: Job Finding Rate: Model vs. Data (left panel) and the Model's Job Finding Rate by UI Status (right panel) (\%) (Data source: CPS)
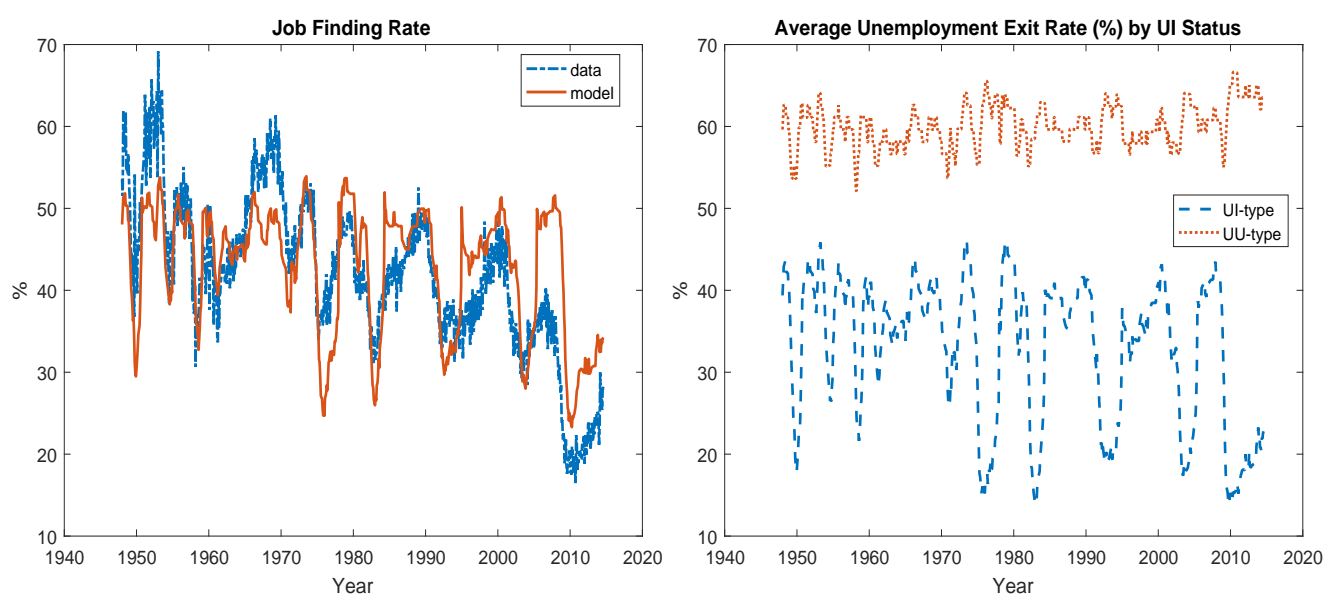
Figure 12: Unemployment (left) and long-term unemployment (right) when using the average maximum potential UI duration across states (average max UI dur.) and the maximum UI duration (max of max UI dur.) (Data source: CPS)
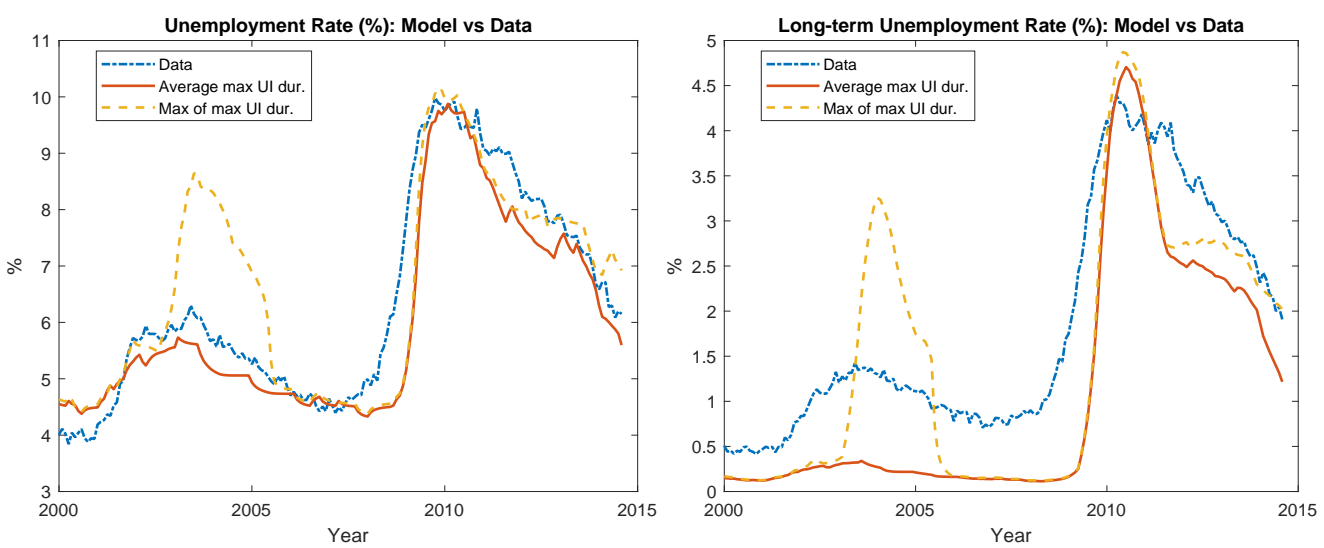

Figure 13: Conditional Job finding rate (top panels) and Total Match Surplus (bottom panels) by UI status $\{e, U I, U U\}$ (left panels) and benefit levels ( $\tilde{m})$ (right panels): For solid (dashed) lines, maximum UI duration is 39 (90) weeks. UI is extended when $u>6.5 \%$.
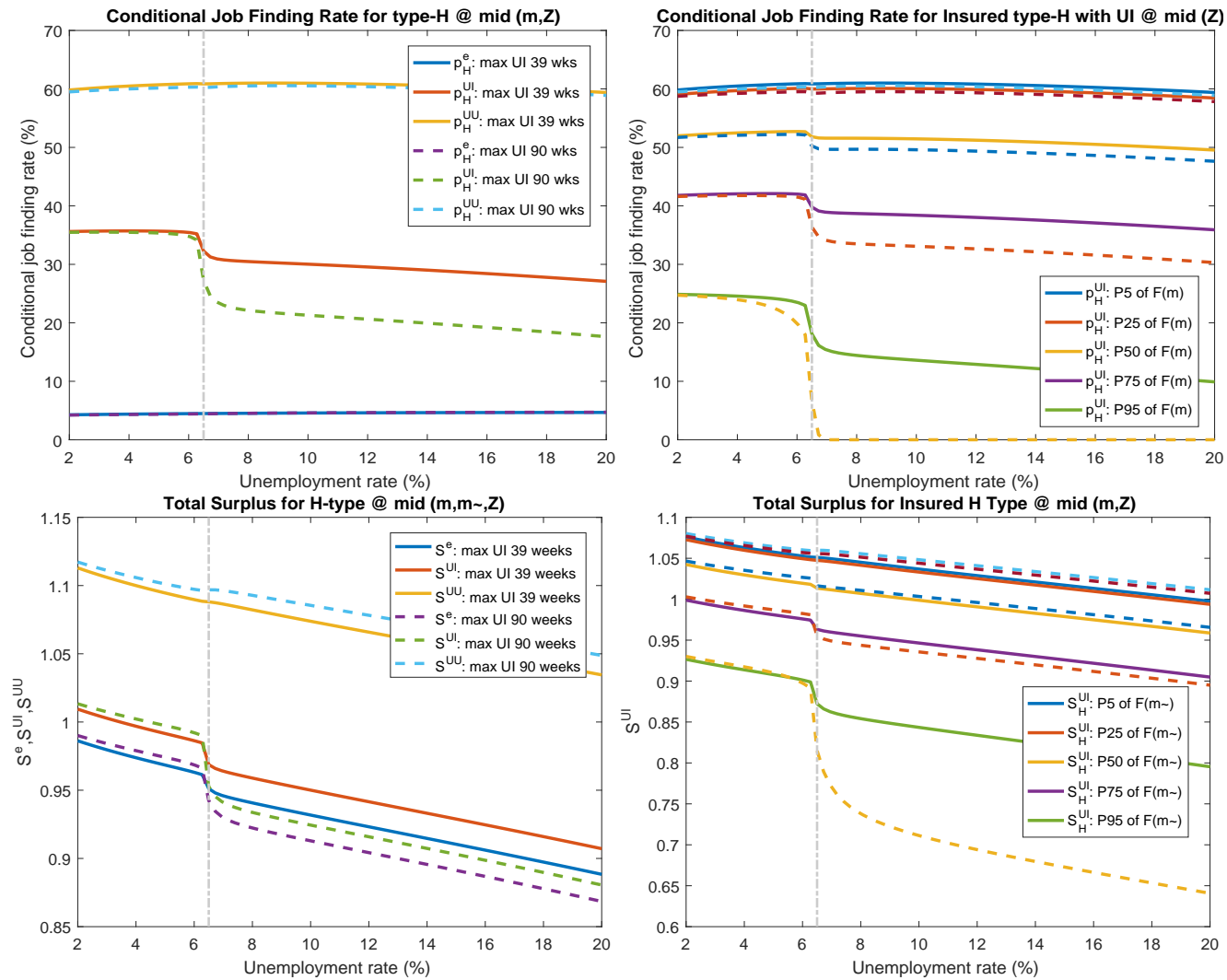
Figure 14: Decomposition of the effect of UI extensions on long-term Unemployment, total unemployment and average unemployment duration: Data, baseline model, and counterfactuals (where each channel does not respond to UI extensions) (Data source: CPS)
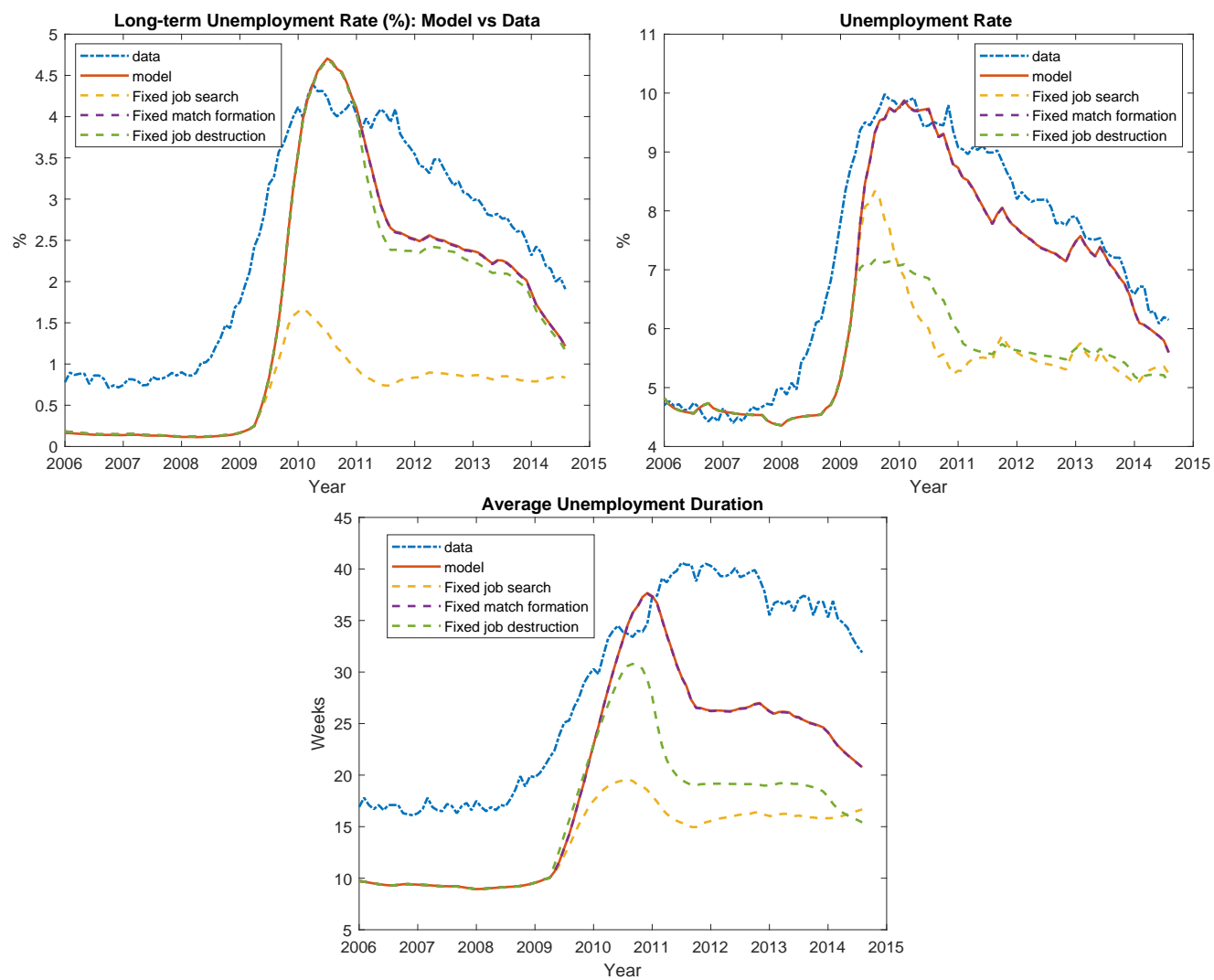

Figure 15: Job Separation Rates from the Start of each Recession (Data source: CPS, NBER)
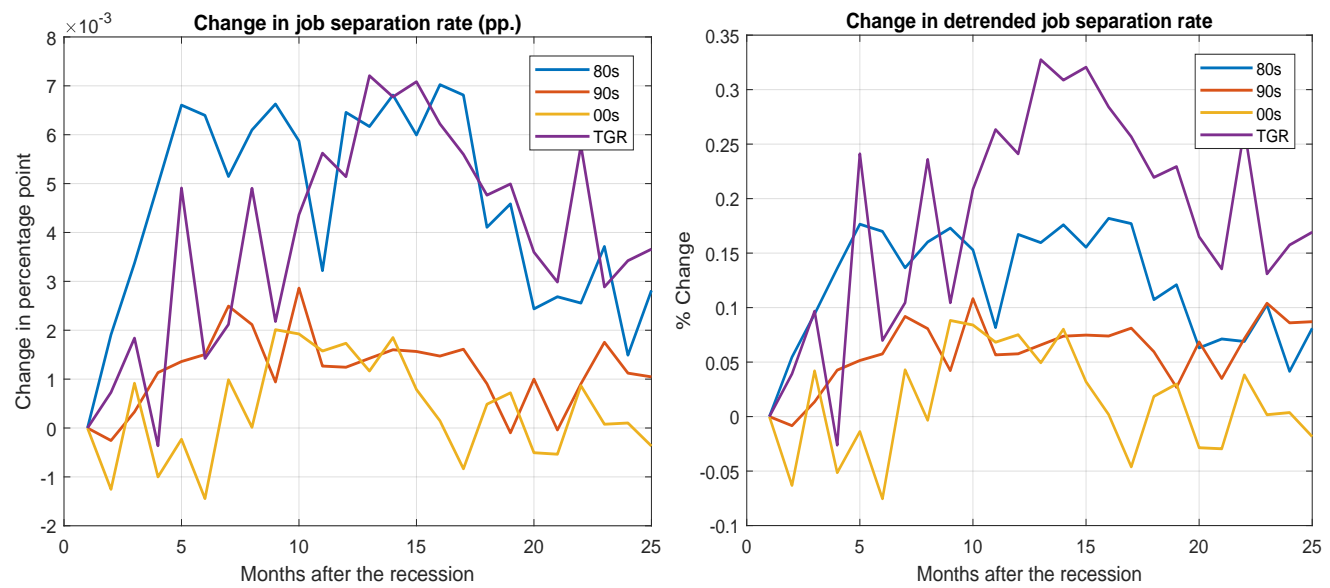

Note: TGR is for the Great Recession. The starting date of each recession is based on NBER. The series in the right panel is detrended using HP filter. 
Figure 16: Hazard Rate (\%) of Exiting Unemployment

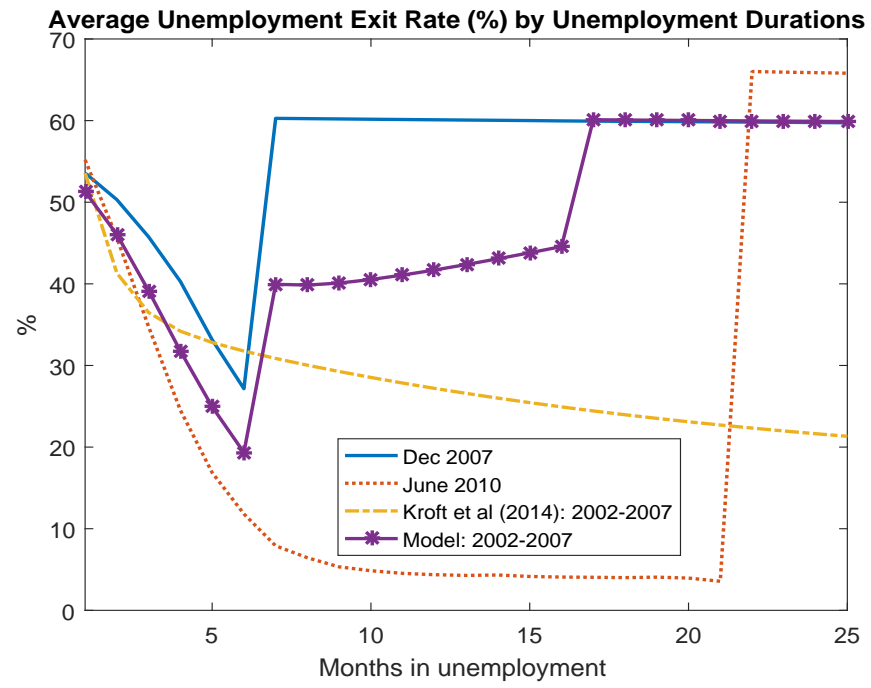

Table 1: Monthly Transition Rate (\%)

\begin{tabular}{l|ccr|ccr}
\hline \hline & \multicolumn{3}{|c|}{ Current UI Recipients } & \multicolumn{3}{c}{ Non-UI Recipients } \\
& Jan-08 & Jan-10 & $\Delta$ pp. & Jan-08 & Jan-10 & $\Delta$ pp. \\
\hline \hline UE & 21.4 & 7.2 & -14.2 & 27.5 & 17.8 & -9.7 \\
UU & 68.4 & 84.4 & +16.0 & 48.0 & 60.2 & +12.2 \\
UOLF & 10.3 & 8.5 & -1.8 & 24.5 & 22.0 & -2.5 \\
\hline
\end{tabular}

- $U$ : Unemployment, $E$ : Employment, $O L F$ : Out of labour force. $\triangle$ pp. $\equiv$ change in rate (in pp.) from January 2008 to January 2010. Data source: CPS. 
Table 2: Targeted Moments

\begin{tabular}{lccc}
\hline \hline Moment & Data & Model & S.E. \\
\hline \hline $\mathrm{E}(u)$ & 0.0583 & 0.0577 & $(0.0095)$ \\
$\mathrm{E}\left(\rho_{U E}\right)$ & 0.4194 & 0.4286 & $(0.0198)$ \\
$\mathrm{E}\left(\rho_{E U}\right)$ & 0.0248 & 0.0251 & $(0.0002)$ \\
$\mathrm{E}\left(\rho_{E E}\right)$ & 0.0320 & 0.0320 & $(0.0096)$ \\
$\mathrm{E}\left(u_{d u r}\right)$ & 14.116 & 13.063 & $(1.2420)$ \\
$\mathrm{E}\left(u^{U I}\right)$ & 0.0290 & 0.0327 & $(0.0079)$ \\
$\operatorname{std}(u)$ & 0.1454 & 0.1453 & $(0.0194)$ \\
$\operatorname{std}\left(\rho_{U E}\right)$ & 0.0999 & 0.1402 & $(0.0138)$ \\
$\operatorname{std}\left(\rho_{E U}\right)$ & 0.0890 & 0.0641 & $(0.0102)$ \\
$\operatorname{std}\left(u_{d u r}\right)$ & 6.9327 & 6.1954 & $(0.5806)$ \\
$\operatorname{std}(L P)$ & 0.0131 & 0.0104 & $(0.0003)$ \\
$\operatorname{corr}(L P, L P-1$ & 0.7612 & 0.7593 & $(0.0181)$ \\
\hline
\end{tabular}

- $\rho_{U E}:$ job finding rate. $\rho_{E U}:$ job separation rate. $\rho_{E E}$ : job-to-job transition rate. $u_{d u r}$ : mean unemployment duration (weeks). $L P=y /(1-u)$ : labour productivity. Data source: CPS

Table 3: Fixed Parameters For Baseline Model

\begin{tabular}{llll}
\hline \hline Parameter & Description & Value & Sources/Remarks \\
\hline \hline$\beta$ & Discount factor & 0.9967 & Annual interest rate of 4\% \\
$\kappa$ & Vacancy posting cost & 0.0392 & Fujita \& Ramey (2012) \\
$\mu$ & Worker's bargaining power & 0.5 & Den Haan, Ramey \& Watson (2000) \\
$\phi_{H}$ & UI exhaustion rate & $1 / 6$ & 6 months max UI duration, ETA \\
$\phi_{L 1}$ & UI exhaustion rate & $1 / 9$ & 9 months max UI duration, ETA \\
$\phi_{L 2}$ & UI exhaustion rate & $1 / 12$ & 12 months max UI duration, ETA \\
$\phi_{L 3}$ & UI exhaustion rate & $1 / 16$ & 16 months max UI duration, ETA \\
$\phi_{L 4}$ & UI exhaustion rate & $1 / 21$ & 21 months max UI duration, ETA \\
$\bar{u}$ & UI policy threshold & 0.065 & ETA \\
$a_{u}$ & Search cost function & 0.1116 & Normalisation \\
$d_{u}, d_{e}$ & Search cost function & 1 & Christensen et al. (2004), Yashiv (2000) \\
$h$ & Leisure flow & 0.5835 & Gruber (1997) \\
\hline
\end{tabular}


Table 4: Values of UI benefits by match quality in most recent employment and worker's productivity

\begin{tabular}{ccccccccccc}
\hline \hline & $m_{10}$ & $m_{20}$ & $m_{30}$ & $m_{40}$ & $m_{50}$ & $m_{60}$ & $m_{70}$ & $m_{80}$ & $m_{90}$ & $m_{100}$ \\
\hline \hline$b_{H}(m)$ & 0.001 & 0.002 & 0.012 & 0.028 & 0.043 & 0.064 & 0.077 & 0.104 & 0.130 & 0.296 \\
\hline$b_{L}(m)$ & 0.001 & 0.002 & 0.012 & 0.027 & 0.042 & 0.062 & 0.076 & 0.103 & 0.129 & 0.295 \\
\hline$m$ & 0.526 & 0.563 & 0.618 & 0.655 & 0.692 & 0.748 & 0.785 & 0.859 & 0.933 & 1.396 \\
\hline
\end{tabular}

- $m_{x}$ is the $x$-th percentile of the match quality distribution $F(m)$

Table 5: Calibrated Parameters For Baseline Model

\begin{tabular}{lll}
\hline \hline Parameter & Description & Value \\
\hline \hline$l$ & Meeting function & 0.51 \\
$\delta$ & Exogenous separation rate & 0.023 \\
$\lambda$ & Pr(redrawing new $m$ ) & 0.50 \\
$\psi$ & Pr(losing UI after becoming unemployed) & 0.49 \\
$\xi$ & Pr(losing UI after meeting firm) & 0.50 \\
$a_{e}$ & Search cost function & 0.15 \\
$m$ & Lowest match-specific productivity & 0.396 \\
$\beta_{1}$ & Match-specific prod. distribution & 2.55 \\
$\beta_{2}$ & Match-specific prod. distribution & 5.26 \\
$\rho_{z}$ & Persistence of TFP & 0.9562 \\
$\sigma_{z}$ & Standard deviation of TFP shocks & 0.0075 \\
$\eta_{L}$ & Productivity of type- $L$ & 0.985 \\
\hline
\end{tabular}

Table 6: Moments Not Targeted

\begin{tabular}{lccc}
\hline \hline Moment & Data & Model & S.E. \\
\hline \hline $\mathrm{E}(U 1)$ & 0.0233 & 0.0237 & $(0.0007)$ \\
$\mathrm{E}(U 2)$ & 0.0172 & 0.0180 & $(0.0014)$ \\
$\mathrm{E}(U 4)$ & 0.0080 & 0.0085 & $(0.0017)$ \\
$\mathrm{E}(L T U)$ & 0.0098 & 0.0076 & $(0.0058)$ \\
$\operatorname{std}(U 1)$ & 0.0048 & 0.0017 & $(0.0005)$ \\
$\operatorname{std}(U 2)$ & 0.0046 & 0.0030 & $(0.0009)$ \\
$\operatorname{std}(U 4)$ & 0.0035 & 0.0035 & $(0.0012)$ \\
$\operatorname{std}(L T U)$ & 0.0085 & 0.0107 & $(0.0057)$ \\
$\operatorname{std}\left(u^{U I}\right)$ & 0.1780 & 0.2523 & $(0.0236)$ \\
$\operatorname{std}(v)$ & 0.1226 & 0.0506 & $(0.0029)$ \\
$\operatorname{corr}(u, v)$ & -0.8786 & -0.2160 & $(0.0241)$ \\
\hline
\end{tabular}

- $U 1$ : Unemployed less than 1 month. $U 2$ : Unemployed with 2-3 month duration. U4: Unemployed with 4-6 month duration. LTU: Unemployed longer 6 months. $u_{d u r}$ : mean unemployment duration (weeks). Data source: CPS 
Table 7: Effects of Eliminating UI Extensions During Recessions

\begin{tabular}{l|c|c|c|c|c}
\hline \hline \multirow{2}{*}{} & & & \multicolumn{3}{|c}{ Change from baseline } \\
\cline { 4 - 6 } & \multirow{2}{*}{ Data } & Baseline & $\Delta \phi$ & $\Delta(\phi, s)$ & $\Delta(\phi, s, S)$ \\
\cline { 4 - 6 } & The Great Recession (From & 90 weeks to 26 weeks of UI) \\
\hline \hline $\max (u)(\%)$ & $10.0 \%$ & $9.8 \%$ & $-0.9 \mathrm{pp}$ & $-1.8 \mathrm{pp}$ & $-2.9 \mathrm{pp}$ \\
$\max \left(u_{d u r}\right)($ weeks) & 40.6 & 37.6 & -23.3 & -25 & -25.6 \\
$\max (L T U)(\%)$ & $4.4 \%$ & $4.7 \%$ & $-3.7 \mathrm{pp}$ & $-4.1 \mathrm{pp}$ & $-4.2 \mathrm{pp}$ \\
\hline
\end{tabular}

The Early 1990s Recession (From 68 weeks to 26 weeks of UI)

\begin{tabular}{l|c|c|c|c|c}
\hline $\max (u)(\%)$ & $7.8 \%$ & $7.8 \%$ & $-0.6 \mathrm{pp}$ & $-1.2 \mathrm{pp}$ & $-1.5 \mathrm{pp}$ \\
$\max \left(u_{\text {dur }}\right)($ weeks $)$ & 20 & 24 & -11.1 & -12.2 & -12.3 \\
$\max (L T U)(\%)$ & $1.7 \%$ & $2.6 \%$ & $-2 \mathrm{pp}$ & $-2.2 \mathrm{pp}$ & $-2.2 \mathrm{pp}$ \\
\hline
\end{tabular}

- $\Delta \phi$ : UI exhaustion rate changes. $\Delta(\phi, s)$ : UI exhaustion rate and job search behaviour change. $\Delta(\phi, s, S)$ : UI exhaustion rate, job search behaviour, match separations, and match formations change. LTU: Unemployed longer 6 months. $u_{d u r}$ : mean unemployment duration. These statistics are computed between October 2009 (the peak of the US unemployment rate) and June 2014 for the Great Recession and between July 1990 and June 1996 for the Early 1990s Recession. Data source: CPS

Table 8: Counterfactual Experiments during the Great Recession

\begin{tabular}{l|c|c|c|c|c}
\hline \hline & Data & Baseline & No Reachback & No Rational Exp. & No OJS \\
\hline \hline $\max (u)(\%)$ & $10.0 \%$ & $9.8 \%$ & $-0.1 \mathrm{pp}$ & $+2.3 \mathrm{pp}$ & $-0.5 \mathrm{pp}$ \\
$\max \left(u_{\text {dur }}\right)($ weeks) & 40.6 & 37.6 & -0.1 & +3.8 & -1.1 \\
$\max (L T U)(\%)$ & $4.4 \%$ & $4.7 \%$ & $-0.1 \mathrm{pp}$ & $+2.1 \mathrm{pp}$ & $-0.4 \mathrm{pp}$ \\
\hline
\end{tabular}

- $L T U$ : Unemployed longer 6 months. $u_{d u r}$ : mean unemployment duration (weeks). These statistics are computed between October 2009 (the peak of the US unemployment rate) and June 2014. Data source: CPS 


\section{A Further Tables (For Online Publication)}

Table A.1: Unemployment-to-Employment (UE) Monthly Transition Rate (\%)

\begin{tabular}{c|ccc|ccc}
\hline \hline & \multicolumn{2}{|c|}{ Current UI Recipients } & \multicolumn{3}{c}{ Non-UI Recipients } \\
& Jan-08 & Jan-10 & $\Delta$ pp. & Jan-08 & Jan-10 & $\Delta$ pp. \\
\hline \hline \multicolumn{7}{c}{ Age } \\
\hline 16 years or older & 21.4 & 7.2 & -14.2 & 27.5 & 17.8 & -9.7 \\
25-54 years & 24.3 & 7.1 & -17.1 & 30.7 & 19.7 & -11.0 \\
\hline \hline \multicolumn{7}{c}{ Gender } \\
\hline Male & 24.9 & 7.2 & -17.6 & 28.4 & 18.3 & -10.1 \\
Female & 16.3 & 7.2 & -9.1 & 26.3 & 17.1 & -9.2 \\
\hline \hline \multicolumn{7}{c}{ Education } \\
\hline Less than High School & 25.0 & 4.7 & -20.3 & 25.4 & 16.2 & -9.2 \\
High School & 9.0 & 7.5 & -1.5 & 28.9 & 16.0 & -12.9 \\
Some College & 27.4 & 7.4 & -20.0 & 28.0 & 20.5 & -7.5 \\
College or higher & 26.8 & 7.4 & -19.3 & 28.4 & 24.5 & -3.9 \\
\hline \hline \multicolumn{7}{c}{ Industry } \\
\hline Manufacturing & 22.5 & 6.5 & -16.0 & 25.6 & 14.9 & -10.7 \\
Construction & 18.3 & 9.6 & -8.7 & 36.3 & 21.6 & -14.7 \\
Wholesale \& Retail & n/a & 6.4 & n/a & 26.0 & 16.3 & -9.7 \\
Prof./Business Services & 45.9 & 4.3 & -41.6 & 22.5 & 19.9 & -2.6 \\
\hline \hline \multicolumn{7}{c}{ Occupation } \\
\hline High-skilled & 27.4 & 7.8 & -19.5 & 27.4 & 24.6 & -2.9 \\
Middle-skilled & 18.6 & 6.6 & -12.0 & 30.1 & 17.9 & -12.2 \\
Low-skilled & 20.6 & 10.4 & -10.2 & 26.6 & 17.6 & -9.0 \\
\hline Temporary Layoff & 50.7 & 12.2 & -38.5 & 46.2 & 40.4 & -5.8 \\
Permanent Separation & 13.6 & 6.7 & -6.9 & 25.6 & 15.6 & -10.0 \\
\hline \hline Dome indication & 48.3 & 13.3 & -35.0 & 36.6 & 33.8 & -2.8 \\
No indication & 16.5 & 7.0 & -9.5 & 22.2 & 17.5 & -4.7 \\
\hline \hline
\end{tabular}

- Data source: CPS. $\Delta$ pp. $\equiv$ change in UE rate (in percentage points) $=$ $U E_{J a n 10}-U E_{J a n 08}$. Occupation skills are defined as in the job polarisation literature (where high-, middle-, and low-skilled occupations respectively are abstract, routine, and manual jobs) 
Table A.2: Unemployment-to-Unemployment (UU) Monthly Transition Rate (\%)

\begin{tabular}{c|ccc|ccc}
\hline \hline & \multicolumn{3}{|c|}{ Current UI Recipients } & \multicolumn{3}{c}{ Non-UI Recipients } \\
& Jan-08 & Jan-10 & $\Delta$ pp. & Jan-08 & Jan-10 & $\Delta$ pp. \\
\hline \hline \multicolumn{7}{c}{ Age } \\
\hline 16 years or older & 68.4 & 84.4 & +16.0 & 48.0 & 60.2 & +12.2 \\
25-54 years & 65.4 & 84.9 & +19.6 & 50.8 & 62.6 & +11.8 \\
\hline \hline \multicolumn{7}{c}{ Gender } \\
\hline Male & 62.5 & 85.5 & +23.0 & 50.9 & 63.0 & +12.1 \\
Female & 77.0 & 81.9 & +4.9 & 43.9 & 56.0 & +12.1 \\
\hline \hline \multicolumn{7}{c}{ Education } \\
\hline Less than High School & 60.7 & 82.4 & +21.7 & 43.8 & 58.1 & +14.3 \\
High School & 77.6 & 87.8 & +10.2 & 49.8 & 63.2 & +13.4 \\
Some College & 65.1 & 81.7 & +16.6 & 49.3 & 58.8 & +9.5 \\
College or higher & 61.1 & 81.2 & +20.1 & 51.7 & 60.4 & +8.8 \\
\hline \hline & \multicolumn{7}{c}{ Industry } \\
\hline Manufacturing & 68.2 & 82.0 & +13.8 & 51.9 & 62.6 & +10.7 \\
Construction & 65.6 & 84.4 & +18.8 & 50.5 & 66.5 & +16.0 \\
Wholesale \& Retail & 80.9 & 86.1 & +5.2 & 49.5 & 60.1 & +10.6 \\
Prof./Business Services & 52.5 & 88.9 & +36.3 & 55.5 & 60.2 & +4.7 \\
\hline \hline
\end{tabular}

- Data source: CPS

$\Delta$ pp. $\equiv$ change in UU rate (in percentage points) $=U U_{\text {Jan } 10}-U U_{\text {Jan } 08}$ Occupation skills are defined as in the job polarisation literature (where high-, middle-, and low-skilled occupations respectively are abstract, routine, and manual jobs) 
Table A.3: Unemployment-to-Out-of-Labour-Force (UOLF) Monthly Transition Rate (\%)

\begin{tabular}{c|ccc|ccc}
\hline \hline & \multicolumn{2}{|c|}{ Current UI Recipients } & \multicolumn{3}{c}{ Non-UI Recipients } \\
& Jan-08 & Jan-10 & $\Delta$ pp. & Jan-08 & Jan-10 & $\Delta$ pp. \\
\hline \hline \multicolumn{7}{c}{ Age } \\
\hline 16 years or older & 10.3 & 8.5 & -1.8 & 24.5 & 22.0 & -2.5 \\
25-54 years & 10.4 & 8.0 & -2.4 & 18.5 & 17.7 & -0.8 \\
\hline \hline \multicolumn{7}{c}{ Gender } \\
\hline Male & 12.6 & 7.3 & -5.4 & 20.7 & 18.7 & -2.0 \\
Female & 6.8 & 10.9 & +4.1 & 29.8 & 26.8 & -3.0 \\
\hline \hline \multicolumn{7}{c}{ Education } \\
\hline Less than High School & 14.3 & 12.9 & -1.4 & 30.8 & 25.7 & -5.1 \\
High School & 13.4 & 4.6 & -8.7 & 21.3 & 20.8 & -0.5 \\
Some College & 7.5 & 11.0 & +3.5 & 22.7 & 20.7 & -2.0 \\
College or higher & 12.1 & 11.3 & -0.8 & 19.9 & 15.1 & -4.8 \\
\hline \hline & \multicolumn{7}{c}{ Industry } \\
\hline Manufacturing & 9.3 & 11.6 & +2.3 & 22.5 & 22.5 & 0.0 \\
Construction & 16.1 & 5.9 & -10.2 & 13.2 & 11.9 & -1.3 \\
Wholesale \& Retail & 19.1 & 7.5 & -11.6 & 24.4 & 23.6 & -0.8 \\
Prof./Business Services & 1.5 & 6.8 & +5.3 & 22.0 & 19.9 & -2.1 \\
\hline \hline
\end{tabular}

- Data source: CPS

$\Delta$ pp. $\equiv$ change in UOLF rate (in percentage points) $=U O L F_{J a n 10}-$ $U O L F_{J a n 08}$

Occupation skills are defined as in the job polarisation literature (where high-, middle-, and low-skilled occupations respectively are abstract, routine, and manual jobs) 
Table A.4: Fraction (\%) of Long-term Unemployment Represented by Current UI Recipients in each Subgroup

\begin{tabular}{c|ccccc|c}
\hline \hline & Jan-06 & Jan-08 & Jan-10 & Jan-12 & Jan-14 & $\begin{array}{c}\Delta \text { pp. from } \\
\text { 2008 to 2010 }\end{array}$ \\
\hline \hline \multicolumn{7}{c}{ Age } \\
\hline 16 years or older & 18 & 15 & 51 & 39 & 16 & +36 \\
25-54 years & 18 & 14 & 50 & 41 & 18 & +36 \\
\hline \hline \multicolumn{7}{c}{ Gender } \\
\hline Male & 15 & 13 & 50 & 38 & 14 & +38 \\
Female & 22 & 18 & 54 & 40 & 19 & +36 \\
\hline \hline Education \\
\hline Less than High School & 13 & 23 & 34 & 32 & 12 & +11 \\
High School & 21 & 2 & 53 & 34 & 14 & +51 \\
Some College & 17 & 21 & 56 & 44 & 17 & +35 \\
College or higher & 22 & 22 & 56 & 40 & 22 & +34 \\
\hline \hline & \multicolumn{7}{c}{ Industry } \\
\hline Manufacturing & 27 & 25 & 62 & 38 & 17 & +37 \\
Construction & 8 & 16 & 47 & 40 & 21 & +31 \\
Wholesale \& Retail & 6 & n/a & 53 & 34 & 18 & n/a \\
Prof./Business Services & 13 & 11 & 43 & 35 & 6 & +32 \\
\hline \hline
\end{tabular}

- Data source: CPS

Long-term unemployment is defined as unemployed workers whose duration is longer than six months.

Occupation skills are defined as in the job polarisation literature (where high-, middle-, and low-skilled occupations respectively are abstract, routine, and manual jobs) 
Table A.5: Fraction (\%) of Newly Unemployed Workers Represented by Current UI Recipients in each Subgroup

\begin{tabular}{|c|c|c|c|c|c|c|}
\hline & Jan-06 & Jan-08 & Jan-10 & Jan-12 & Jan-14 & $\begin{array}{c}\Delta \text { pp. from } \\
2008 \text { to } 2010\end{array}$ \\
\hline \multicolumn{7}{|c|}{$\overline{\text { Age }}$} \\
\hline 16 years or older & 23 & 21 & 41 & 30 & 25 & +20 \\
\hline 25-54 years & 24 & 21 & 42 & 33 & 31 & +21 \\
\hline \multicolumn{7}{|c|}{ Gender } \\
\hline Male & 26 & 20 & 40 & 33 & 27 & +20 \\
\hline Female & 18 & 23 & 42 & 26 & 21 & +19 \\
\hline \multicolumn{7}{|c|}{ Education } \\
\hline Less than High School & 23 & 18 & 25 & 28 & 8 & +7 \\
\hline High School & 29 & 17 & 48 & 27 & 33 & +30 \\
\hline Some College & 16 & 26 & 41 & 33 & 26 & +14 \\
\hline College or higher & 18 & 24 & 46 & 33 & 30 & +22 \\
\hline \multicolumn{7}{|c|}{ Industry } \\
\hline Manufacturing & 45 & 30 & 44 & 36 & 31 & +15 \\
\hline Construction & 33 & 17 & 44 & 45 & 32 & +27 \\
\hline Wholesale \& Retail & 25 & 21 & 51 & 20 & 24 & +30 \\
\hline Prof./Business Services & 13 & 19 & 26 & 33 & 22 & +7 \\
\hline \multicolumn{7}{|c|}{ Occupation } \\
\hline High-skilled & 22 & 24 & 55 & 34 & 30 & +31 \\
\hline Middle-skilled & 26 & 18 & 41 & 36 & 25 & +23 \\
\hline Low-skilled & 6 & 30 & 22 & 12 & 18 & -8 \\
\hline \multicolumn{7}{|c|}{ "Reasons for Unemployment } \\
\hline Temporary Layoff & 34 & 25 & 44 & 27 & 31 & +19 \\
\hline Permanent Separation & 25 & 21 & 47 & 33 & 28 & +26 \\
\hline \multicolumn{7}{|c|}{ Recall } \\
\hline Date Given & 25 & 25 & 49 & 23 & 24 & +24 \\
\hline No Date Given & 32 & 30 & 49 & 34 & 36 & +20 \\
\hline Some indication & 39 & 26 & 42 & 31 & 40 & +16 \\
\hline No indication & 28 & 31 & 51 & 34 & 35 & +19 \\
\hline
\end{tabular}

- Data source: CPS

Newly unemployed workers are defined as unemployed workers whose duration is less than five weeks.

Occupation skills are defined as in the job polarisation literature (where high-, middle-, and low-skilled occupations respectively are abstract, routine, and manual jobs) 


\section{B Expressions for Optimal Search Intensity and Match Surplus}

Given the worker's value functions when employed, insured unemployed and uninsured unemployed, we can take the first derivative to find the optimal search effort. The first order conditions for type- $i$ workers are as follows

$$
\begin{aligned}
v_{e}^{\prime}\left(s_{i}^{e}(m ; \omega)\right)= & -\beta(1-\delta) M(\theta(\omega)) E_{\omega^{\prime} \mid \omega}[\ldots \\
& (1-\lambda)(1-F(m))\left(W S_{i}^{e(m)+}\left(m ; \omega^{\prime}\right)-E_{m^{\prime} \mid m^{\prime}>m}\left[W S_{i}^{e(m)+}\left(m^{\prime} ; \omega^{\prime}\right)\right]\right) \\
+ & \left.\lambda E_{m^{\prime}}\left[\left(1-F\left(m^{\prime}\right)\right)\left(W S_{i}^{e(m)+}\left(m^{\prime} ; \omega^{\prime}\right)-E_{m^{\prime \prime} \mid m^{\prime \prime}>m^{\prime}}\left[W S_{i}^{e(m)+}\left(m^{\prime \prime} ; \omega^{\prime}\right)\right]\right)\right]\right] \\
v_{u}^{\prime}\left(s_{i}^{U I}(m, \omega)\right)= & \beta M(\theta(\omega)) E_{m^{\prime} \omega^{\prime} \mid \omega}\left[\max \left\{W S_{i}^{U I(m)}\left(m^{\prime} ; \omega^{\prime}\right), 0\right\}-\xi(1-\phi(u)) U S_{i}\left(m, \omega^{\prime}\right)\right] \\
v_{u}^{\prime}\left(s_{i}^{U U}(\omega)\right)= & \beta M(\theta(\omega)) E_{m^{\prime} \omega^{\prime} \mid \omega}\left[\max \left\{W S_{i}^{U U}\left(m^{\prime} ; \omega^{\prime}\right), 0\right\}\right]
\end{aligned}
$$

Total match surpluses and unemployed worker's surplus are as follows

$$
\begin{aligned}
S_{i}^{e(\tilde{m})}(m ; \omega)= & y_{i}(m, \omega)-v_{e}\left(s_{i}^{e}(m ; \omega)\right)-\tau(\omega)-(1-\psi)\left(b_{i}(\tilde{m})+h-v_{u}\left(s_{i}^{U I(\tilde{m})}(\omega)\right)\right) \\
& -\psi\left(h-v_{u}\left(s_{i}^{U U}(\omega)\right)\right)+\beta E_{\omega^{\prime} \mid \omega}[\ldots \\
& (1-\delta)(1-\lambda)\left(\left(1-p_{i}^{e}(m ; \omega)(1-F(m))\right) S_{i}^{e(m)+}\left(m ; \omega^{\prime}\right) \ldots\right. \\
& \left.+p_{i}^{e}(m ; \omega)(1-F(m)) E_{m^{\prime} \mid m^{\prime}>m}\left[\mu S_{i}^{e(m)+}\left(m^{\prime} ; \omega^{\prime}\right)\right]\right) \\
& +(1-\delta) \lambda E_{m^{\prime}}\left[\left(1-p_{i}^{e}(m ; \omega)\left(1-F\left(m^{\prime}\right)\right)\right) S_{i}^{e(m)+}\left(m^{\prime} ; \omega^{\prime}\right) \ldots\right. \\
& \left.+p_{i}^{e}(m ; \omega)\left(1-F\left(m^{\prime}\right)\right) E_{m^{\prime \prime} \mid m^{\prime \prime}>m^{\prime}}\left[\mu S_{i}^{e(m)+}\left(m^{\prime \prime} ; \omega^{\prime}\right)\right]\right] \\
& -(1-\psi) p_{i}^{U I(\tilde{m})}(\omega) E_{m^{\prime}}\left[\mu S_{i}^{U I(\tilde{m})+}\left(m^{\prime} ; \omega^{\prime}\right)\right] \\
& -\psi p_{i}^{U U}(\omega) E_{m^{\prime}}\left[\mu S_{i}^{U U}\left(m^{\prime} ; \omega^{\prime}\right)\right] \\
& +(1-\psi)\left(U S_{i}\left(m, \omega^{\prime}\right)-U S_{i}\left(\tilde{m}, \omega^{\prime}\right) \ldots\right. \\
& \left.\left.+\left(\phi(u)+p_{i}^{U I(\tilde{m})}(\omega) \xi(1-\phi(u))\right) U S_{i}\left(\tilde{m}, \omega^{\prime}\right)\right)\right]
\end{aligned}
$$




$$
\begin{aligned}
S_{i}^{U I(\tilde{m})}(m ; \omega)= & y_{i}(m, \omega)-v_{e}\left(s_{i}^{e}(m ; \omega)\right)-\tau \\
& -(1-\phi)(1-\xi)\left(b(\tilde{m})+h-v_{u}\left(s_{i}^{U I(\tilde{m})}(\omega)\right)\right) \\
& -(1-(1-\phi)(1-\xi))\left(h-v_{u}\left(s_{i}^{U U}(\omega)\right)\right)+\beta E_{\omega^{\prime} \mid \omega}[\ldots \\
& (1-\delta)(1-\lambda)\left(\left(1-p_{i}^{e}(m ; \omega)(1-F(m))\right) S_{i}^{e(m)+}\left(m ; \omega^{\prime}\right) \ldots\right. \\
& \left.+p_{i}^{e}(m ; \omega)(1-F(m)) E_{m^{\prime} \mid m^{\prime}>m}\left[\mu S_{i}^{e(m)+}\left(m^{\prime} ; \omega^{\prime}\right)\right]\right) \\
& +(1-\delta) \lambda E_{m^{\prime}}\left[\left(1-p_{i}^{e}(m ; \omega)\left(1-F\left(m^{\prime}\right)\right)\right) S_{i}^{e(m)+}\left(m^{\prime} ; \omega^{\prime}\right) \ldots\right. \\
& \left.+p_{i}^{e}(m ; \omega)\left(1-F\left(m^{\prime}\right)\right) E_{m^{\prime \prime} \mid m^{\prime \prime}>m^{\prime}}\left[\mu S_{i}^{e(m)+}\left(m^{\prime \prime} ; \omega^{\prime}\right)\right]\right] \\
& -(1-\phi)(1-\xi) p_{i}^{U I(\tilde{m})}(\omega) E_{m^{\prime}}\left[\mu S_{i}^{U I(\tilde{m})+}\left(m^{\prime} ; \omega^{\prime}\right)\right] \\
& -(1-(1-\phi)(1-\xi)) p_{i}^{U U}(\omega) E_{m^{\prime}}\left[\mu S_{i}^{U U+}\left(m^{\prime} ; \omega^{\prime}\right)\right] \\
& +(1-\psi) U S_{i}\left(m, \omega^{\prime}\right) \\
& \left.-\left((1-\phi)^{2}(1-\xi)\left(1-\xi p_{i}^{U I(\tilde{m})}(\omega)\right)\right) U S_{i}\left(\tilde{m}, \omega^{\prime}\right)\right]
\end{aligned}
$$

$$
\begin{aligned}
S_{i}^{U U}(m ; \omega)= & y_{i}(m, \omega)-v_{e}\left(s_{i}^{e}(m ; \omega)\right)-\tau-\left(h-v_{u}\left(s_{i}^{U U}(\omega)\right)\right)+\beta E_{\omega^{\prime} \mid \omega}[\ldots \\
& (1-\delta)(1-\lambda)\left(\left(1-p_{i}^{e}(m ; \omega)(1-F(m))\right) S_{i}^{e(m)+}\left(m ; \omega^{\prime}\right) \ldots\right. \\
& \left.+p_{i}^{e}(m ; \omega)(1-F(m)) E_{m^{\prime} \mid m^{\prime}>m}\left[\mu S_{i}^{e(m)+}\left(m^{\prime} ; \omega^{\prime}\right)\right]\right) \\
& +(1-\delta) \lambda E_{m^{\prime}}\left[\left(1-p_{i}^{e}(m ; \omega)\left(1-F\left(m^{\prime}\right)\right)\right) S_{i}^{e(m)+}\left(m^{\prime} ; \omega^{\prime}\right) \ldots\right. \\
& \left.+p_{i}^{e}(m ; \omega)\left(1-F\left(m^{\prime}\right)\right) E_{m^{\prime \prime} \mid m^{\prime \prime}>m^{\prime}}\left[\mu S_{i}^{e(m)+}\left(m^{\prime \prime} ; \omega^{\prime}\right)\right]\right] \\
& -p_{i}^{U U}(\omega) E_{m^{\prime}}\left[\mu S_{i}^{U U+}\left(m^{\prime} ; \omega^{\prime}\right)\right] \\
& \left.+(1-\psi) U S_{i}\left(m, \omega^{\prime}\right)\right]
\end{aligned}
$$

$$
\begin{aligned}
U S_{i}(m, \omega)= & b(m)-v_{u}\left(s_{i}^{U I(m)}(\omega)\right)+v_{u}\left(s_{i}^{U U}(\omega)\right) \\
& +\beta E_{\omega^{\prime} \mid \omega}\left[p_{i}^{U I(m)}(\omega) E_{m^{\prime}}\left[\mu S_{i}^{U I(m)+}\left(m^{\prime} ; \omega^{\prime}\right)\right] \ldots\right. \\
& -p_{i}^{U U}(\omega) E_{m^{\prime}}\left[\mu S_{i}^{U U+}\left(m^{\prime} ; \omega^{\prime}\right)\right] \\
& \left.+(1-\phi)\left(1-\xi p_{i}^{U I(m)}(\omega)\right) U S_{i}\left(m, \omega^{\prime}\right)\right]
\end{aligned}
$$




\section{Transitions}

Employment The mass of type- $i$ employed agents in $t$ with match quality $m$, $e_{i, t}(m)$, evolves as follows

$$
\begin{aligned}
e_{i, t+1}(m)= & (1-\delta)(1-\lambda)\left(1-p_{i, t}^{e}(m)+p_{i, t}^{e}(m) F(m)\right) e_{i, t}(m) \mathbb{1}\left\{S_{i, t+1}^{e(m)}(m)>0\right\} \\
& +(1-\delta)(1-\lambda) f(m) \int_{m^{\prime}<m} p_{i, t}^{e}\left(m^{\prime}\right) e_{i, t}\left(m^{\prime}\right) \mathbb{1}\left\{S_{i, t+1}^{e\left(m^{\prime}\right)}(m)>0\right\} d m^{\prime} \\
& +(1-\delta) \lambda f(m) \int_{m^{\prime}}\left(1-p_{i, t}^{e}\left(m^{\prime}\right)+p_{i, t}^{e}\left(m^{\prime}\right) F(m)\right) e_{i, t}\left(m^{\prime}\right) \mathbb{1}\left\{S_{i, t+1}^{e\left(m^{\prime}\right)}(m)>0\right\} d m^{\prime} \\
& +(1-\delta) \lambda F(m) f(m) \int_{m^{\prime}} p_{i, t}^{e}\left(m^{\prime}\right) e_{i, t}\left(m^{\prime}\right) \mathbb{1}\left\{S_{i, t+1}^{e\left(m^{\prime}\right)}(m)>0\right\} d m^{\prime} \\
& +f(m) \int_{\tilde{m}} u_{i, t}^{U I}(\tilde{m}) p_{i, t}^{U I}(\tilde{m}) \mathbb{1}\left\{S_{i, t+1}^{U I(\tilde{m})}(m)>0\right\} d \tilde{m} \\
& +f(m) u_{i, t}^{U U} p_{i, t}^{U U} \mathbb{1}\left\{S_{i, t+1}^{U U}(m)>0\right\}
\end{aligned}
$$

where $\mathbb{1}\{\cdot\}$ is an indicator function. The total employment is the sum of all employed workers over productivity types and match qualities $e_{t}=\sum_{i=H, L} \int e_{i, t}(m) d m$, and the aggregate output can be computed as $y_{t}=z_{t} \sum_{i=H, L} \int m \cdot e_{i, t}(m) d m$.

Job Destructions The job destruction rate of type- $i$ employed workers with match quality $m$ at the beginning of period $t$ and $m^{\prime}$ at the end of period $t$ and the average job destruction rate are respectively

$$
\begin{aligned}
\rho_{x, i t}\left(m, m^{\prime}\right)= & \begin{cases}\delta & \text { if } S_{i, t+1}^{e(m)}\left(m^{\prime}\right)>0, \\
1 & \text { otherwise }\end{cases} \\
\rho_{x, i t}= & \left(\delta \iint_{\left\{\left(m, m^{\prime}\right): S_{i, t+1}^{e(m)}\left(m^{\prime}\right)>0\right\}} e_{i, t}^{\text {post }}\left(m, m^{\prime}\right) d m d m^{\prime}\right. \\
& \left.+\iint_{\left\{\left(m, m^{\prime}\right): S_{i, t+1}^{e(m)}\left(m^{\prime}\right) \leq 0\right\}} e_{i, t}^{\text {post }}\left(m, m^{\prime}\right) d m d m^{\prime}\right) / e_{t}
\end{aligned}
$$

$$
\begin{aligned}
\text { where } e_{i, t}^{\text {post }}\left(m, m^{\prime}\right)= & (1-\lambda)\left(1-p_{i, t}^{e}\left(m^{\prime}\right)+p_{i, t}^{e}\left(m^{\prime}\right) F\left(m^{\prime}\right)\right) e_{i, t}\left(m^{\prime}\right) \\
& +(1-\lambda) f\left(m^{\prime}\right) p_{i, t}^{e}(m) e_{i, t}(m) \mathbb{1}\left\{m<m^{\prime}\right\} \\
& +\lambda f\left(m^{\prime}\right)\left(1-p_{i, t}^{e}(m)+p_{i, t}^{e}(m) F\left(m^{\prime}\right)\right) e_{i, t}(m) \\
& +\lambda F\left(m^{\prime}\right) f\left(m^{\prime}\right) p_{i, t}^{e}(m) e_{i, t}(m)
\end{aligned}
$$


denotes employed workers with match productivity $m$ at the beginning of period $t$ and $m^{\prime}$ at the end of the period $t$.

Job Findings The job finding rate for a type- $i$ unemployed worker of status $j=\{U I(\tilde{m}), U U\}$ and the average job finding rate are respectively

$$
\begin{aligned}
\rho_{f, i t}^{j} & =\int \rho_{f, i t}^{j}(m) f(m) d m \\
\rho_{f, t} & =\frac{\int_{\tilde{m}} u_{i, t}^{U I}(\tilde{m}) \rho_{f, i t}^{U I(\tilde{m})} d \tilde{m}+u_{i, t}^{U U} \rho_{f, i t}^{U U}}{\int_{\tilde{m}} u_{t}^{U I}(\tilde{m}) d \tilde{m}+u_{t}^{U U}} \\
\text { where } \rho_{f, i t}^{j}(m) & = \begin{cases}p_{i, t}^{j} & \text { if } S_{i, t+1}^{j}(m)>0, \\
0 & \text { otherwise }\end{cases}
\end{aligned}
$$

Job-to-job Transitions The match-specific and the average job-to-job transition rates are respectively

$$
\begin{aligned}
\rho_{i, t}^{e e}(m)= & (1-\delta)\left((1-\lambda) p_{i, t}^{e}(m)(1-F(m)) E_{m^{\prime}>m}\left[\mathbf{1}\left\{S_{i, t+1}^{e}\left(m, m^{\prime}\right)>0\right\}\right]\right. \\
& \left.+\lambda \int_{m^{\prime}} p_{i, t}^{e}(m) f\left(m^{\prime}\right)\left(1-F\left(m^{\prime}\right)\right) E_{m^{\prime \prime}>m^{\prime}}\left[\mathbf{1}\left\{S_{i, t+1}^{e}\left(m, m^{\prime \prime}\right)>0\right\}\right] d m^{\prime}\right) \\
\rho_{i, t}^{e e}= & \frac{\int_{m} \rho_{i, t}^{e e}(m) e_{i, t}(m) d m}{e_{t}}
\end{aligned}
$$

Unemployment The mass of type-i unemployed workers with and without UI benefits as well as the total unemployment evolve respectively as follows

$$
\begin{aligned}
u_{i, t+1}^{U I}(\tilde{m})= & \underbrace{\left(1-\phi_{t}\right)\left(1-p_{i, t}^{U I}(\tilde{m})\right) u_{i, t}^{U I}(\tilde{m})}_{\text {unmatched, not losing UI }}+\underbrace{\chi_{i, t}^{U I}(\tilde{m})\left(1-\phi_{t}\right)(1-\xi) p_{i, t}^{U I}(\tilde{m}) u_{i, t}^{U I}(\tilde{m})}_{\text {bad match, not losing UI }} \\
& +\underbrace{(1-\psi) \int_{m^{\prime}} \rho_{x, i t}\left(\tilde{m}, m^{\prime}\right) e_{i, t}\left(\tilde{m}, m^{\prime}\right) d m^{\prime}}_{\text {destroyed match, not losing UI }} \\
u_{i, t+1}^{U U}= & \int_{\tilde{m}}^{(\underbrace{\phi_{t}\left(1-p_{i, t}^{U I}(\tilde{m})\right) u_{i, t}^{U I}(\tilde{m})}_{\text {unmatched, losing UI }}+\underbrace{\chi_{i, t}^{U I}(\tilde{m})\left(\phi_{t}+\left(1-\phi_{t}\right) \xi\right) p_{i, t}^{U I}(\tilde{m}) u_{i, t}^{U I}(\tilde{m})}_{\text {bad match, losing UI }}) d \tilde{m}} \\
& +\left(1-\rho_{f, i t}^{U U}\right) u_{i, t}^{U U}+\underbrace{\psi \rho_{x, i t} e_{i, t}}_{\text {destroyed match, losing UI }} \\
u_{t+1}= & \sum_{i=H, L}\left(\int_{\tilde{m}} u_{i, t+1}^{U I}(\tilde{m}) d \tilde{m}+u_{i, t+1}^{U U}\right)
\end{aligned}
$$


where $\chi_{i, t}^{U I}(\tilde{m}) \equiv \int \mathbf{1}\left\{S_{i, t+1}^{U I}(\tilde{m}, m) \leq 0\right\} f(m) d m$ denotes the rate the newly formed matches with $u_{i}^{U I}(\tilde{m})$ are not viable.

\section{Performance of the Approximation Method}

Table D.1 reports the average percentage deviations (in modulus) of the first four moments of the approximated distribution of employed workers over match quality, employment history, and individual productivity. This approximated distribution is on average less than $1 \%$ different in terms of the 1 st, $2 \mathrm{nd}$, and 4 th moments from the simulated distributions. The $3 \mathrm{rd}$ moment is however more than $3 \%$ different from the simulation which is mainly due to the different cut-off points in the distributions coming from the endogenous job separations.

Table D.1: Performance of the Approximation Method

\begin{tabular}{ccc}
\hline \hline & \multicolumn{2}{c}{ Percentage deviations (\%) } \\
& Mean & SE \\
\hline \hline 1st moment & 0.4762 & 0.3512 \\
2nd moment & 0.3164 & 0.4641 \\
3rd moment & 3.5648 & 3.324 \\
4th moment & 0.1982 & 0.2564 \\
\hline
\end{tabular}

\section{E On the Sources of Long-term Unemployment (For Online Publication)}

In this section I first show how consistent the model's unemployment series are with the empirical data by estimating a non-linear state space model in Ahn and Hamilton (2019) using the model's generated data. Then I study the implications on the sources of long-term unemployment. They explore the roles of worker's unobserved heterogeneity on unemployment dynamics. Their interpretation is that there are two types of workers: type- $H$ workers have an ex-ante higher rate of exiting unemployment than do type- $L$ workers. They also allow for genuine duration dependence that could be positive (motivational effect) and 
negative (scarring effect). The measurements or observables in their model are unemployment series by 5 duration bins $\left\{u_{t}^{1}, u_{t}^{2.3}, u_{t}^{4.6}, u_{t}^{7.12}, u_{t}^{13+}\right\}$ which are, respectively, unemployed workers with duration less than 1 month, 2-3 months, 4-6 months, 7-12 months, and more than 12 months. The latent or hidden states are also time varying. They are the number of newly unemployed workers for each type and a factor governing the unemployment continuation probability for each type. I summarise their state space model in Appendix F.

I obtain 50 different series of $\left\{u_{t}^{1}, u_{t}^{2.3}, u_{t}^{4.6}, u_{t}^{7.12}, u_{t}^{13+}\right\}$ using the Monte Carlo simulations from the baseline model. For each set of the simulated unemployment series, I use Maximum Likelihood to obtain a set of (twelve) estimates from the state space model as described in Appendix F. The extended Kalman filter is used to construct the likelihood function since some latent variables enter the equations for unemployment series non-linearly. Table F.1 reports these estimates and their standard errors.

Overall, the model's estimates are consistent with the empirical ones in Ahn and Hamilton (2019). Based on these estimated parameters, I construct the series for (1) the probability that newly unemployed workers of each type stay unemployed the following month, (2) the number of newly unemployed workers of each type, and (3) the share of unemployment by each type. Comparisons between these series and their empirical counterparts from Ahn and Hamilton (2019) are shown in Figures E.1, E.2, and E.3 respectively.

The probabilities that the newly unemployed workers stay unemployed in the following month from the model's estimates (Figure E.1) exhibit more volatility over the business cycles especially for type- $L$ workers. Nonetheless, during the Great Recession, the model's data implies the rise of this probability for type- $L$ workers and a small drop for type- $H$ workers similar to its empirical counterpart. Going back to the model's results, we can see from the right panel of Figure 11 in the manuscript that they complement well with the results from this estimation where the insured unemployed workers (the type with "lower" exit rate) have a much more volatile unemployment exit rate than the uninsured (the type with "higher" exit rate).

With respect to the number of newly unemployed during the Great Recession (Figure E.2), the model's estimates also imply a spike of the inflow of type- $L$ workers (and a much smaller rise for type- $H$ ) with similar magnitude to the empirical counterpart. However, since the UI status of newly unemployed workers 
in the model is governed solely by the poisson rate $\psi$, the series for the newly unemployed workers who are insured and uninsured are perfectly correlated and therefore do not complement the results in Figure E.2. The series only differ as the workers remain unemployed which is related to Figure E.3, showing the shares of total unemployment by unobserved types. The model's implied share has very similar dynamics to the data throughout the observed periods. However, the share of type- $L$ workers does not show a clear negative trend like in Ahn and Hamilton (2019), but this is expected since the model does not account for any low frequency changes or a trend e.g. in the unemployment rate or the job finding rate. Figure E. 4 shows the model's shares of total unemployment by UI status and worker's productivity. It can be seen that the rise in the share of type- $L$ workers from the estimation (Figure E.3) has more similar dynamics to the share of the insured unemployed workers in the model (rather than the share of the low productivity workers which exhibits smaller fluctuations).

Figure E.5 shows the implied unemployment continuation probabilities from the true duration dependence component which are similar to the empirical estimates. This probability is rather constant in the first 6 months of duration, and then it increases during 6-12 months of unemployment implying a scarring effect. After 12 months of unemployment, it is more likely that a worker exits unemployment the longer she stays unemployed. These estimates are somewhat consistent with the model's hazard rate of exiting unemployment (Figure 16) discussed in subsection 5.7 of the manuscript. As the UI benefits run out, workers search harder for jobs and exit unemployment more quickly. The change in the job search behaviour (and therefore the hazard rate) depends on the maximum UI duration, but we can observe that in the 1976-2014 periods (upon which the observations are based) the maximum UI duration during recessions is at least 12 months which is consistent with a fall in the probability of remaining unemployed after 12 months.

In summary, the model's unemployment series are consistent with the empirical data as estimated using a state space model. I can relate Ahn and Hamilton (2019)'s interpretation of worker unobserved heterogeneity to the UI statuses of unemployed workers in my model since the insured unemployed have a lower unemployment exit rate than do the uninsured. They have similar dynamics in terms of the unemployment exit rate as well as the shares of total unemployment. Moreover, some feature of the genuine duration dependence in the job finding 
Figure E.1: Probability that the newly unemployed workers of each type remain unemployed the following month: model's prediction (left panel) and empirical prediction from Ahn \& Hamilton (2019) (right panel, source: Ahn \& Hamilton, 2019)
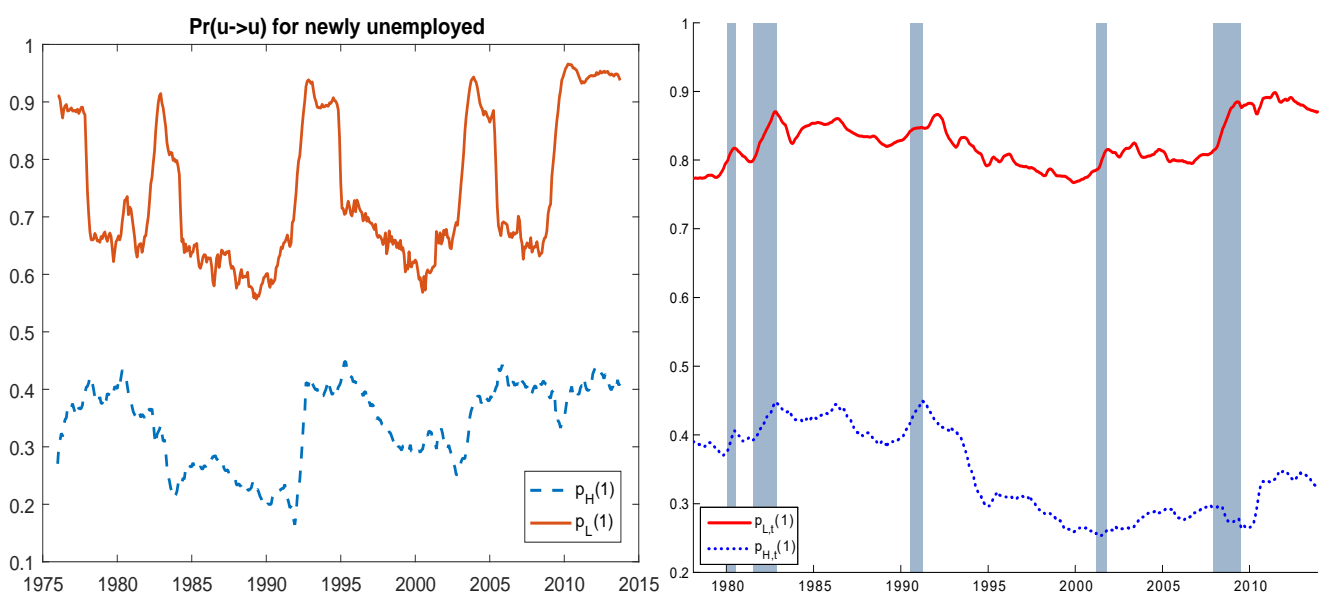

rate can also be related to the UI exhaustion in the model. 
Figure E.2: Number of newly unemployed workers of each type: model's prediction (left panel) and empirical prediction from Ahn \& Hamilton (2019) (right panel, source: Ahn \& Hamilton, 2019)
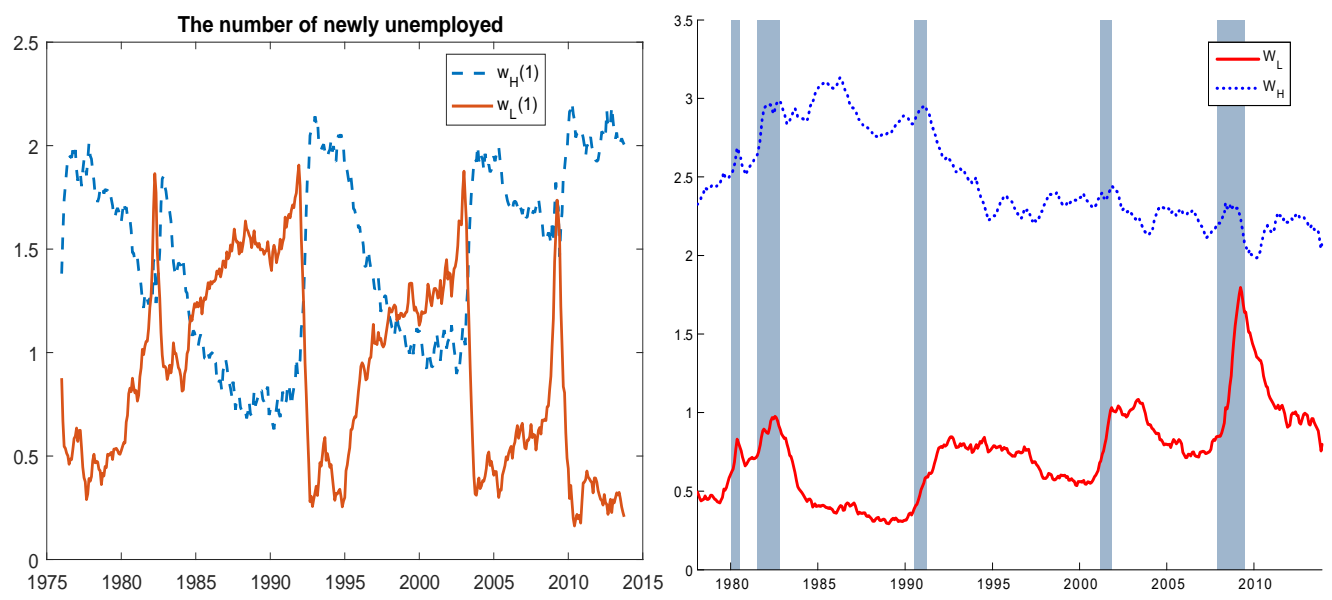

Figure E.3: Share of unemployment by worker's type: model's prediction (left panel) and empirical prediction from Ahn \& Hamilton (2019) (right panel, source: Ahn \& Hamilton, 2019)
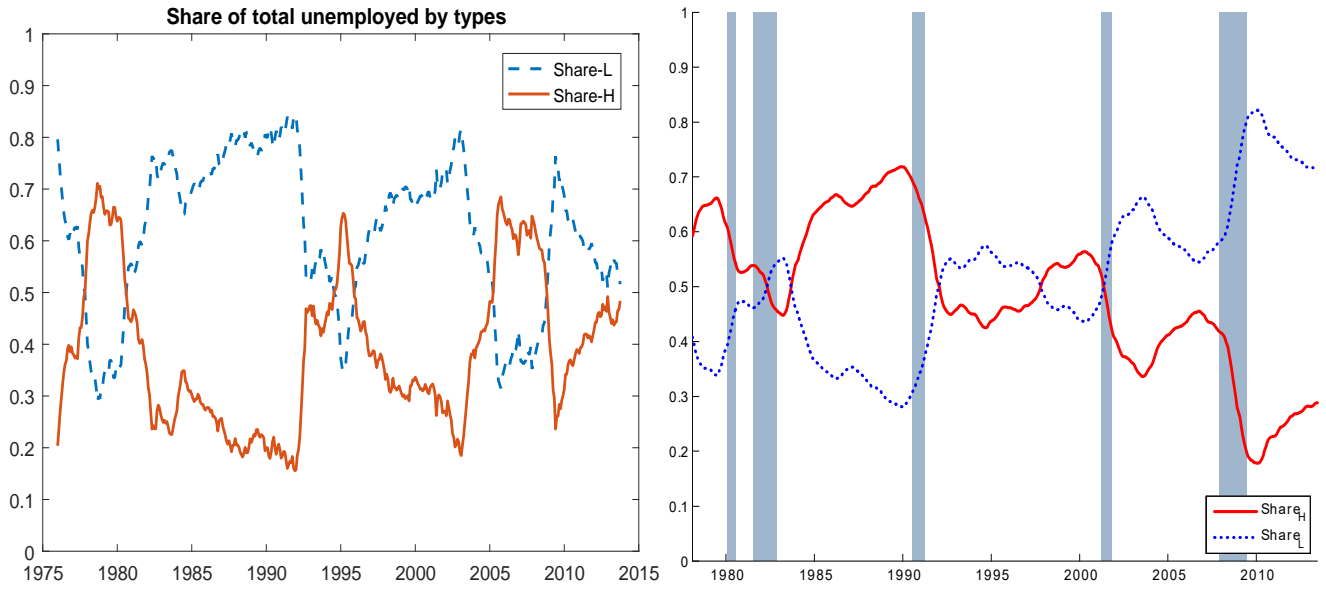
Figure E.4: Shares (\%) of unemployment by UI Status and Worker's Productivity

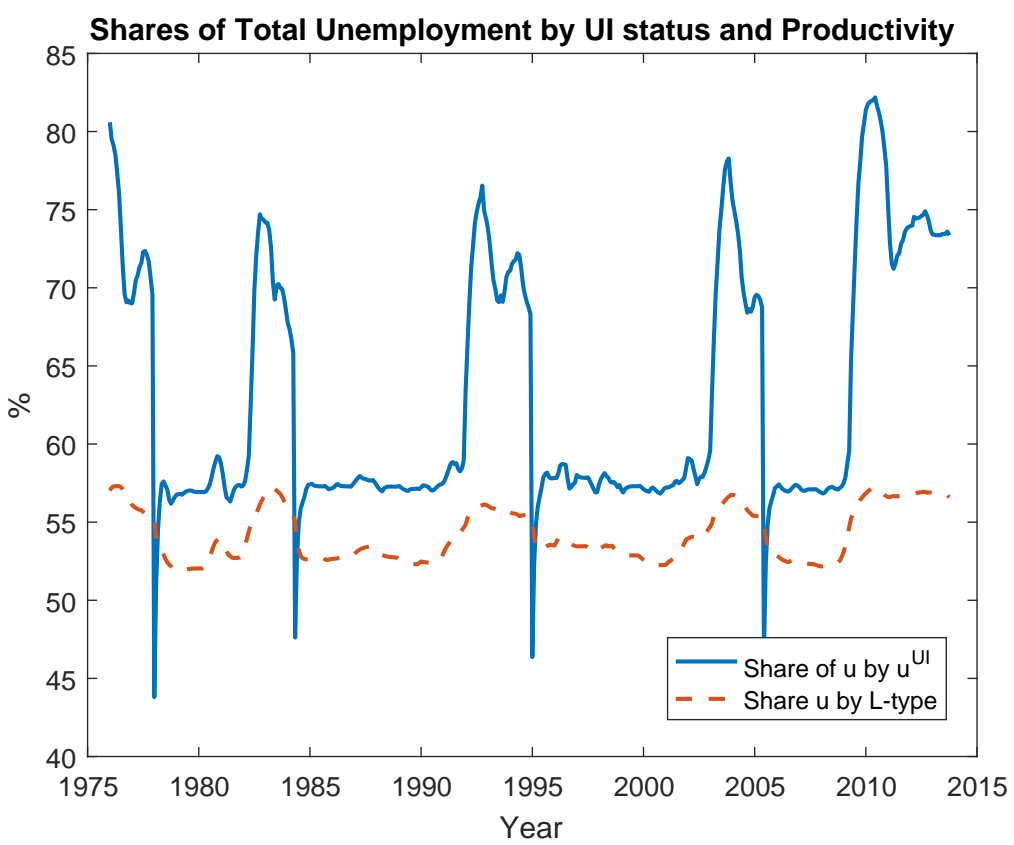

Figure E.5: Implied Unemployment Continuation Probability from Genuine Duration Dependence: model's prediction (solid) and empirical prediction from Ahn \& Hamilton (2019) (dashed)

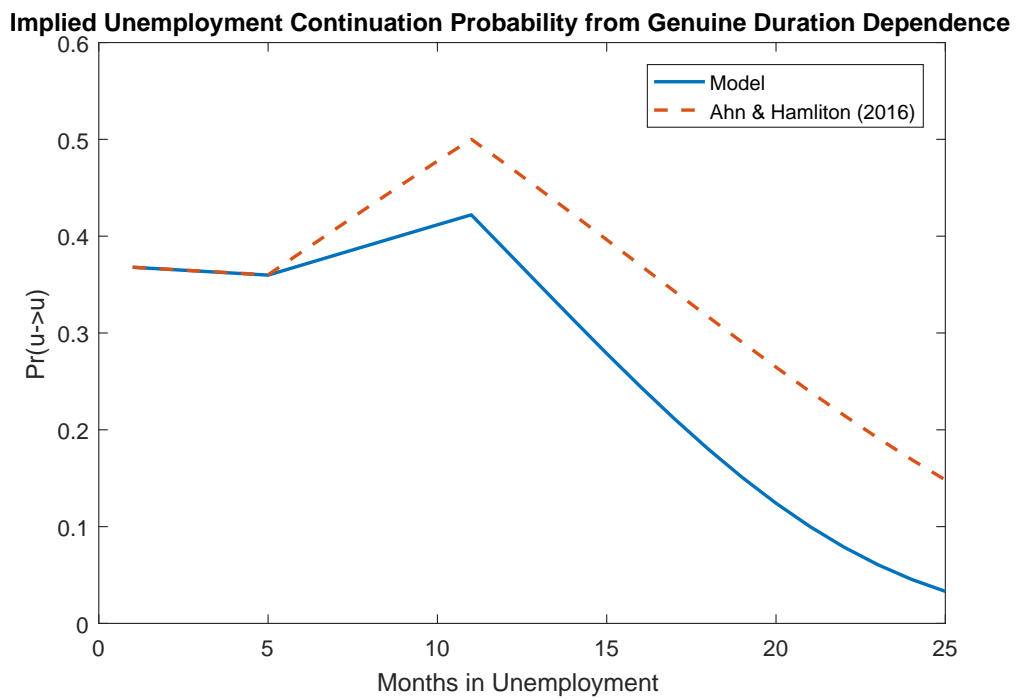

- Note: The time varying factors governing the outflow rates for type- $i$ workers $\left(x_{i t}\right)$ are normalised to zero when calculating these probabilities. 


\section{F Ahn and Hamilton (2019)'s State Space Model (For Online Publication)}

To summarise briefly, Ahn and Hamilton (2019)'s state space model contains the latent variables which are the number of each type entering unemployment in each time period $\left(w_{H, t}, w_{L, t}\right)$ and the time-varying factors governing their outflow rates $\left(x_{H, t}, x_{L, t}\right)$. These four variables follow a random walk process. For example, $w_{H, t}=w_{H, t-1}+\varepsilon_{H, t}^{w}$. The errors are independently and normally distributed with mean zero and standard deviation $\left\{\sigma_{H}^{w}, \sigma_{L}^{w}, \sigma_{H}^{x}, \sigma_{L}^{x}\right\}$ respectively. They assume the true duration dependence of unemployment exit rate is time invariant and summarised by $\left\{\delta_{1}, \delta_{2}, \delta_{3}\right\}$. The measurements or observables in their model are unemployment series by 5 duration bins $\left\{u_{t}^{1}, u_{t}^{2.3}, u_{t}^{4.6}, u_{t}^{7.12}, u_{t}^{13+}\right\}$. They are, respectively, unemployed workers with duration less than 1 month, 2-3 months, 4-6 months, 7-12 months, and more than 12 months. All five unemployment series can contain measurement errors $\left\{r_{t}^{1}, r_{t}^{2.3}, r_{t}^{4.6}, r_{t}^{7.12}, r_{t}^{13+}\right\}$ which are independently and normally distributed with mean zero and standard deviation $\{R 1, R 2.3, R 4.6, R 7.12, R 13+\}$. The evolution of these series are as follows

$$
\begin{aligned}
u_{t}^{1} & =\sum_{i=H, L} w_{i t}+r_{t}^{1} \\
u_{t}^{2.3} & =\sum_{i=H, L}\left[w_{i, t-1} P_{i t}(1)+w_{i, t-2} P_{i t}(2)\right]+r_{t}^{2.3} \\
u_{t}^{4.6} & =\sum_{i=H, L} \sum_{k=3}^{5}\left[w_{i, t-k} P_{i t}(k)\right]+r_{t}^{4.6} \\
u_{t}^{7.12} & =\sum_{i=H, L} \sum_{k=6}^{11}\left[w_{i, t-k} P_{i t}(k)\right]+r_{t}^{7.12} \\
u_{t}^{13+} & =\sum_{i=H, L} \sum_{k=12}^{47}\left[w_{i, t-k} P_{i t}(k)\right]+r_{t}^{13+}
\end{aligned}
$$

where $P_{i t}(j)=p_{i, t-j+1}(1) \times p_{i, t-j+2}(2) \times \ldots \times p_{i, t}(j)$

$$
\begin{aligned}
& p_{i t}(\tau)= \exp \left[-\exp \left(x_{i t}+d_{\tau}\right)\right] \\
& d_{\tau}=\left\{\begin{array}{lr}
\delta_{1}(\tau-1) & \text { for } \tau<6 \\
\delta_{1}[(6-1)-1]+\delta_{2}[\tau-(6-1)] & \text { for } 6 \leq \tau<12 \\
\delta_{1}[(6-1)-1]+\delta_{2}[(12-1)-(6-1)]+\delta_{3}[\tau-(12-1)] & \text { for } 12 \leq \tau
\end{array}\right.
\end{aligned}
$$


The parameters to be estimated are the standard deviations of the errors $\left\{\sigma_{H}^{w}, \sigma_{L}^{w}, \sigma_{H}^{x}, \sigma_{L}^{x}\right.$, $R 1, R 2.3, R 4.6, R 7.12, R 13+\}$ and the parameters for true duration dependence $\left\{\delta_{1}, \delta_{2}, \delta_{3}\right\}$. I obtain 50 different series of $\left\{u_{t}^{1}, u_{t}^{2.3}, u_{t}^{4.6}, u_{t}^{7.12}, u_{t}^{13+}\right\}$ by using the Monte Carlo simulations. For each set of the simulated unemployment series, I obtain a set of twelve estimates from the same non-linear state space model using Maximum Likelihood. The extended Kalman filter is used to construct the likelihood function since $\left\{x_{H, t}, x_{L, t}\right\}$ enter the equations for unemployment series non-linearly. Table F.1 reports these estimates and their standard errors. 
Table F.1: Parameter Estimates from State Space Model in Ahn and Hamilton (2019)

\begin{tabular}{lcc}
\hline \hline Parameter & A\&H (2016) & Model \\
\hline \hline$\sigma_{L}^{w}$ & 0.0434 & 0.0439 \\
& $(0.0041)$ & $(0.0086)$ \\
$\sigma_{H}^{w}$ & 0.0456 & 0.0487 \\
& $(0.0059)$ & $(0.0060)$ \\
$\sigma_{L}^{x}$ & 0.0446 & 0.0469 \\
& $(0.0049)$ & $(0.0096)$ \\
$\sigma_{H}^{x}$ & 0.0209 & 0.0211 \\
& $(0.0028)$ & $(0.0030)$ \\
$\delta_{1}$ & 0.0053 & 0.0055 \\
& $(0.0138)$ & $(0.0010)$ \\
$\delta_{2}$ & -0.0647 & -0.0283 \\
& $(0.0242)$ & $(0.0383)$ \\
$\delta_{3}$ & 0.0724 & 0.0981 \\
& $(0.0250)$ & $(0.0231)$ \\
$R 1$ & 0.0981 & 0.0966 \\
& $(0.0058)$ & $(0.0156)$ \\
$R 2.3$ & 0.0759 & 0.0755 \\
& $(0.0043)$ & $(0.0111)$ \\
$R 4.6$ & 0.0775 & 0.0765 \\
$R 7.12$ & $(0.0068)$ & $(0.0123)$ \\
& 0.0597 & 0.0626 \\
$R 13+$ & $(0.0051)$ & $(0.0080)$ \\
& 0.0366 & 0.0390 \\
& $(0.0026)$ & $(0.0057)$ \\
\hline
\end{tabular}

- Standard errors are reported in parentheses. Please refer to Appendix E for variables' definitions 